\title{
Cellulose-based hydrogel materials: chemistry, properties and their prospective applications
}

\author{
S M Fijul Kabir ${ }^{1}$ (1) $\cdot$ Partha P. Sikdar ${ }^{2}$ B. Haque ${ }^{3}$ M. A. Rahman Bhuiyan ${ }^{4} \cdot$ A. Ali ${ }^{4}$ M. N. Islam ${ }^{5}$
}

Received: 6 June 2018 / Accepted: 25 August 2018 / Published online: 4 September 2018

(c) The Author(s) 2018

\begin{abstract}
Hydrogels based on cellulose comprising many organic biopolymers including cellulose, chitin, and chitosan are the hydrophilic material, which can absorb and retain a huge proportion of water in the interstitial sites of their structures. These polymers feature many amazing properties such as responsiveness to $\mathrm{pH}$, time, temperature, chemical species and biological conditions besides a very high-water absorption capacity. Biopolymer hydrogels can be manipulated and crafted for numerous applications leading to a tremendous boom in research during recent times in scientific communities. With the growing environmental concerns and an emergent demand, researchers throughout the globe are concentrating particularly on naturally derived hydrogels due to their biocompatibility, biodegradability and abundance. Cellulose-based hydrogels are considered as useful biocompatible materials to be used in medical devices to treat, augment or replace any tissue, organ, or help function of the body. These hydrogels also hold a great promise for applications in agricultural activity, as smart materials and some other useful industrial purposes. This review offers an overview of the recent and contemporary research regarding physiochemical properties of cellulose-based hydrogels along with their applications in multidisciplinary areas including biomedical fields such as drug delivery, tissue engineering and wound healing, healthcare and hygienic products as well as in agriculture, textiles and industrial applications as smart materials.
\end{abstract}

S M Fijul Kabir

mahin.tex.7393@gmail.com

1 Department of Textiles, Apparel Design and Merchandising,

Louisiana State University, Baton Rouge, LA 70803, USA

2 Department of Textiles, Merchandising and Interiors, University of Georgia, Athens, GA 30602, USA

3 College of Textile Engineering, University of Chittagong, Chittagong 4331, Bangladesh

4 Department of Textile Engineering, Dhaka University of Engineering and Technology, DUET, Gazipur 1700, Bangladesh

5 Department of Chemistry, Dhaka University of Engineering and Technology, DUET, Gazipur 1700, Bangladesh 


\section{Graphical abstract}

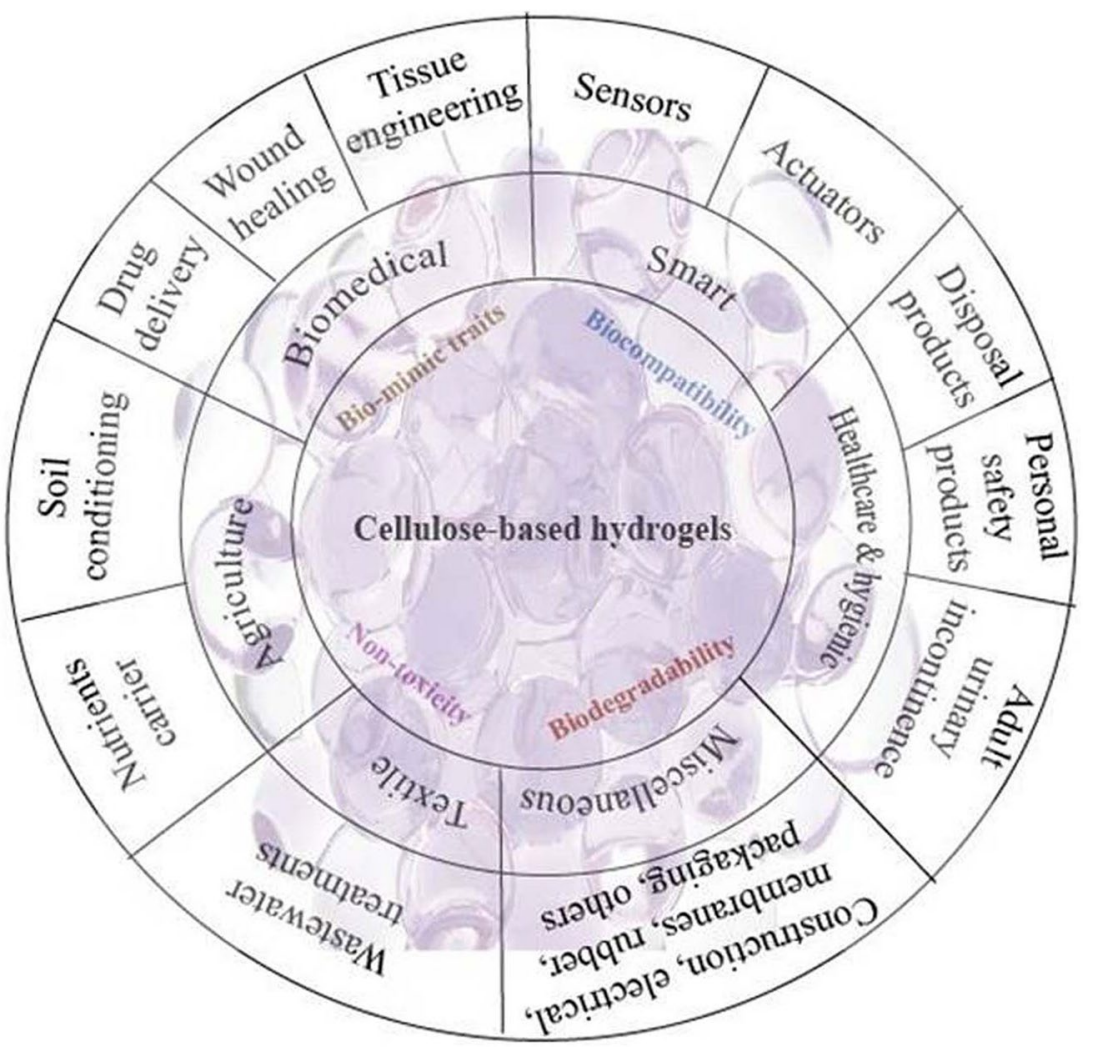

Keywords Hydrogels $\cdot$ Cellulose $\cdot$ Chitin $\cdot$ Chitosan $\cdot$ Smart material $\cdot$ Biomedical applications

\section{Introduction}

Hydrogels are polymeric materials with three-dimensional (3D) network structure having hydrophilic polymer chains as well as their ability to absorb and retain a large volume of water in their interstitial structures (Chai et al. 2017; Ebara et al. 2014; Yuan 2013). Upon contact with water, hydrogels continue to absorb and swell to form $3 \mathrm{D}$ structure due to the presence of hydrophilic groups, such as- $\mathrm{NH}_{2},-\mathrm{OH},-\mathrm{COOH},-\mathrm{SO}_{3} \mathrm{H}$ in their polymer networks and osmotic pressure (Yuan 2013). The ability to hold an unaltered 3D structure during swelling is caused by physical or chemical crosslinking that also helps prevent hydrogels from dissolution in the solvent (Rizwan et al. 2017). Physical crosslinking is a temporal connection due to hydrogen bonding, hydrophobic interactions or electrostatic interactions between polar groups. On the other hand, chemical crosslinking is a permanent junction formed by covalent bonds, along with a relatively stronger ionic communication between various functional groups of introduced crosslinking agents (Ahmed 2015). Therefore, different polymeric structures including homo-polymers, linear copolymers, and block or graft copolymers are formed because of physical and/or chemical crosslinking during the polymerization process (Hoffman 2012). Besides, hydrogels are being used in various physical forms, which could be solid molded forms (soft contact lenses), pressed powder matrices (pills or capsules for oral ingestion), microparticles (as bio-adhesive carriers or wound treatments), coatings (on implants or catheters), membranes or sheets (as a reservoir in a transdermal drug delivery patch), encapsulated solids (in osmotic pumps) and liquids (that form gels upon heating or cooling) (Ebara et al. 2014).

Hydrogels are generally availed from the natural source (natural hydrogels) or synthesized through chemical reactions. Naturally sourced hydrogels often called biopolymer-based hydrogels, have some idiosyncratic attributes unlike synthetic hydrogels in terms of biocompatibility, biodegradability, non-toxicity, bio-mimic traits (Mogoşanu and Grumezescu 2014). However, some synthetic hydrogels or chemically modified hydrogels (hybrid hydrogels) find some improved features nowadays in terms of functionality, which makes them more attractive than natural hydrogels. Biopolymer-based hydrogels are sourced 
mainly from the plant and/or animal extract (Shen et al. 2016) as well as from cellulose, which are termed as cellulose-based (CB) hydrogels. These hydrogels can be prepared from pure and native cellulose by chemical dissolution with $\mathrm{LiCl} /$ dimethylacetamide (DMAc), $\mathrm{N}$-methylmorpholine- $\mathrm{N}$-oxide (NMMO), ionic liquids (ILs), alkali/urea (or thiourea), or by fabricating/designing with bacterial cellulose (Shen et al. 2016). Cellulose derivatives are comprised usually of either esters (e.g., cellulose acetate (CA), cellulose acetate phthalate (CAP), cellulose acetate butyrate $(\mathrm{CAB})$, cellulose acetate trimellitate (CAT), hydroxypropyl methylcellulose phthalate (HPMCP)) or ethers (e.g., methylcellulose (MC), ethyl cellulose (EC), hydroxyethyl cellulose (HEC), carboxymethyl cellulose (CMC), sodium carboxymethyl cellulose (NaCMC), hydroxypropyl cellulose (HPC) and hydroxypropyl methylcellulose (HPMC)). Another recent type is composite hydrogels made up of blending composites with natural polymers, polyvinyl alcohol, polyelectrolyte complexes, interpenetrating polymer network, celluloseinorganic hybrid hydrogels (Chang and Zhang 2011; Onofrei and Filimon 2016; Sannino et al. 2009).

The appealing functionalities of CB hydrogels inspire researchers throughout the globe to develop new materials for myriad applications in various fields, such as biomedical engineering (tissue engineering, wound dressing, drug delivery system), development of smart materials (sensors, actuators), advancement in healthcare and hygienic products (diapers, napkins) along with improvement in agriculture (pesticide carriers, water reservoir, water retention). The research boom in the different array of CB hydrogels has ensued hundreds of patents and numerous research articles, which have been published in recent times (Rodrigues et al. 2014). The trend of published patents over the last decades concerning CB hydrogels and their various applications are presented in Fig. 1.

Besides, a significant number of review articles have also been published on polysaccharide and its derivatives including cellulose regarding different contexts as shown in Table 1. These review articles are mainly focused on the preparation and design of CB hydrogels along with their biomedical, agricultural and hygienic applications separately. However, to the best of our knowledge, a comprehensive review with a broad picture of CB hydrogel including their hygienic and non-hygienic applications are not discussed yet. Hence, the aim of the present review is to concentrate on the current research on biopolymer cellulose-based hydrogels as well as analyze the scope of their wide range of applications in various fields. The organization of this article is devoted to the chemical structure of cellulose-based hydrogels, highlighting the physicochemical properties of these polymers followed by applications in wide-ranging fields as well as underscoring the effects of polymer characteristics

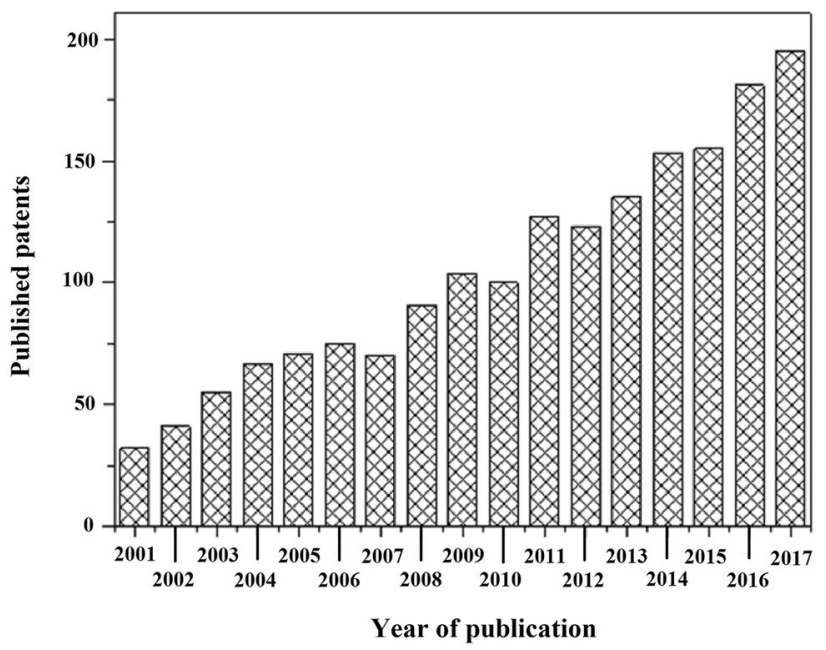

Fig. 1 An overview of the number of published patents concerning cellulose-based hydrogels over the last decades

on their applications through a meticulous analysis of the contemporary and recent studies.

\section{Natural hydrogels and their derivatives}

Natural hydrogels are commonly derived from polysaccharide and protein derivatives (Le et al. 2017). Cellulose and its derivative based hydrogels are developed from polysaccharides (Kwiecień and Kwiecień 2018). Considering the context of the review, natural hydrogels from cellulose and its derivatives have been further classified as shown in Fig. 2.

\section{Native/pure cellulose-based hydrogels}

Hydrogels based on natural cellulose can be prepared from a pure cellulose solution through physical cross-linking due to the presence of numerous hydroxyl groups, which can link polymer network through hydrogen bonding (Shen et al. 2016). Cellulose is the most abundant naturally occurring polymer of glucose (Fig. 3a), which are found in plants and natural fibers such as cotton and linen (Bhuiyan et al. 2017; Edgar et al. 2001; Islam et al. 2017). Moreover, chitin, chitosan and bacterial cellulose, comprising hydroxyl groups can also be used as alternative sources of cellulose to develop hydrogels with fascinating structures and properties (Chang and Zhang 2011). The hydroxyl group at position C-2 of cellulose chain has been replaced by an acetamide $\left(\mathrm{CH}_{3} \mathrm{CONH}-\right)$ group in chitin structure (Fig. 3b). If the acetamide groups of chitin are transformed into primary amino groups, they would turn into $N$-deacetylated derivatives being called chitosan (Fig. 3c) (Aranaz et al. 2009). Microbial or bacterial cellulose (BC), synthesized from bacteria (e.g., acetobacterxylinum) (Ross et al. 1991; Sannino 
Table 1 Published review articles on different aspects of polysaccharide and its derivative-based hydrogels

\begin{tabular}{|c|c|c|}
\hline $\begin{array}{l}\text { Polysaccharide and its deriva- } \\
\text { tive-based hydrogels }\end{array}$ & Context of the review & References \\
\hline Polysaccharide-based & $\begin{array}{l}\text { Characterization and properties } \\
\text { Release formulations } \\
\text { Preparation, characterization and agricultural applications } \\
\text { Protein drug delivery applications }\end{array}$ & $\begin{array}{l}\text { Magnani et al. (2000) } \\
\text { Coviello et al. (2007) } \\
\text { Guilherme et al. (2015) } \\
\text { Chen et al. (1995) }\end{array}$ \\
\hline Psyllium polysaccharide-based & $\begin{array}{l}\text { Structure, synthesis, and biomedical, flocculation and water treatment applica- } \\
\text { tions }\end{array}$ & Thakur and Thakur (2014) \\
\hline Chitosan-based & $\begin{array}{l}\text { Characteristics and pharmaceutical applications } \\
\text { Controlled, localized drug delivery applications } \\
\text { Characteristics and pharmaceutical applications } \\
\text { Nasal drug delivery applications }\end{array}$ & $\begin{array}{l}\text { Ahmadi et al. (2015) } \\
\text { Bhattarai et al. (2010) } \\
\text { Ahmadi et al. (2015) } \\
\text { Luppi et al. (2010) }\end{array}$ \\
\hline Cellulose-based & $\begin{array}{l}\text { Smart swelling and controllable delivery applications } \\
\text { Biomedical applications } \\
\text { Preparation, and agricultural, hygienic, water treatment and biomedical applica- } \\
\text { tions } \\
\text { Biomedical and environmental applications } \\
\text { Design, and hygienic, agricultural and biomedical applications }\end{array}$ & $\begin{array}{l}\text { Chang et al. (2010) } \\
\text { Chang and Zhang (2011) } \\
\text { Ma et al. (2015) }\end{array}$ \\
\hline Cellulose and chitin-based & Fabrication, properties, and biomedical and water treatment applications & Shen et al. (2016) \\
\hline Cellulose/chitin composites & Preparation and characterization & Rodrigues et al. (2014) \\
\hline Starch-based & $\begin{array}{l}\text { Synthesis, and agricultural, water treatment, biomedical, electrical and construc- } \\
\text { tion applications } \\
\text { Fabrication and biomedical applications } \\
\text { Synthesis, hygienic, medical, constructional, agricultural and other applications }\end{array}$ & $\begin{array}{l}\text { Ismail et al. (2013) } \\
\text { Zhang et al. (2005) } \\
\text { Athawale and Lele (2001) }\end{array}$ \\
\hline Cellulose-derivatives-based & Dermal and transdermal drug delivery analysis and applications & Vlaia et al. (2016) \\
\hline Carboxymethyl cellulose-based & Water treatment applications & Yang et al. (2011) \\
\hline
\end{tabular}

et al. 2009), has the chemical group like plant cellulose (PC), but they have different macromolecular structures and physical properties. In both BC and PC, the glucose units are held together by 1,4- $\beta$-glucosidic linkages (Czaja et al. 2007), which hold the cellulose polymer, resulting in the linear chain polymer having a large number of $-\mathrm{OH}$ groups. This strong structure can be propagated to molecules containing 1000-1500 $\beta$-D-gluclose monomeric units (Aravamudhan et al. 2014).

\section{Cellulose derivatives}

Most of the water-soluble cellulose derivatives are obtained by etherification of cellulose, where the active hydroxyl groups of cellulose react with organic species, such as methyl and ethyl units (Tosh 2015) (Fig. 4). Cellulose ether derivatives include methylcellulose (MC), ethylcellulose (EC), hydroxyethyl methylcellulose (HEMC), hydroxypropyl cellulose (HPC) and sodium carboxymethyl cellulose (CMCNa) (Marques-Marinho and Vianna-Soares 2013). The average number of etherified hydroxyl groups in a glucose unit determines the degree of substitution, which is controlled in such a way that cellulose derivatives can acquire the desired solubility and viscosity in water solutions (Mischnick and Momcilovic 2010).

Cellulose ester derivatives are also used in the pharmaceutical domain for their unique functional properties. Here, these polymers are formed by esterification of cellulosic hydroxyl and various organic acids in the presence of a strong acid as a catalyst (Fig. 5); for example, cellulose acetate, acetate trimellitate, acetate phthalate, hydroxypropylmethylphthalate and hydroxypropylmethylphthalate acetate succinate (Marques-Marinho and Vianna-Soares 2013).

\section{Cellulose-based composite hydrogels}

Cellulose-based composite hydrogels are made by blending natural biodegradable polymers or synthetic polymers with cellulose or its derivatives such as chitin, chitosan (Long and Luyen 1996; Mahmoudian and Ganji 2017) and starch (Faroongsarng and Sukonrat 2008) to achieve a new structural design and functional properties (Bajpai et al. 2008). For instance, phase-separated composite hydrogels have been prepared by blending cellulose and chitin in thiourea aqueous solution in the presence of $\mathrm{H}_{2} \mathrm{SO}_{4}$ as coagulant (Zhou et al. 2004). Cellulose powder and chitosan solution are mixed together to form cellulose/chitosan hydrogel 


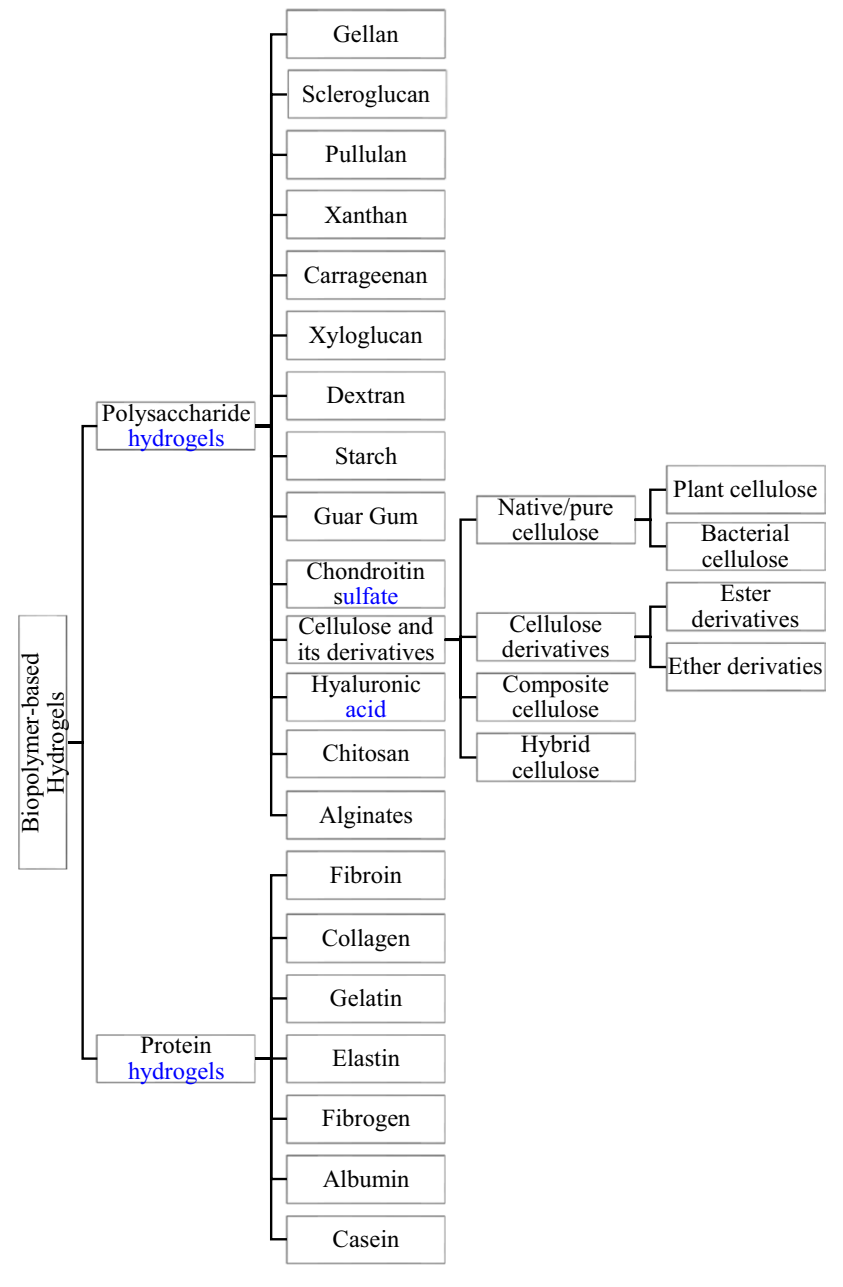

Fig. 2 Classification of natural hydrogels based on source

beads, which are crosslinked with ethylene glycol diglycidyl ether to make them considerably denser and chemically stable for $\mathrm{Cu}$ adsorption applications (Li and Bai 2005). In addition, cellulose/starch composite gel can be prepared by keeping their homogeneous mixture for several days (Kadokawa et al. 2009). CB composite hydrogels can also be prepared from a synthetic polymer like polyvinyl alcohol (PVA).

CB composite hydrogels with PVA are cross-linked using several methods, including chemical agents, electron beam or physically thermal cycling (Ivanov et al. 2007). Another special type of water-soluble hydrogel called polyelectrolyte complexes can be constructed by introducing other positively charged polyelectrolytes in the presence of CMC (Papadakis and Tsitsilianis 2017). Chitosan and CMC solution are blended to form an amphoteric hydrogel membrane followed by crosslinking with glutaraldehyde. This hydrogel is flexible and can bend toward either anode or cathode, depending on the $\mathrm{pH}$ of the solution (Sperling 1994). CB composite hydrogels can be fabricated by interpenetrating polymer networks (IPNs). It is the combination of two or more polymers in the network that are synthesized in juxtaposition. Generally, two types of IPNs including sequential IPN and semi-IPN are employed for the fabrication of such hydrogels. For sequential IPN, cellulose is used as the primary network, and the secondary network is formed by polymerization in the presence of the cellulose network and in case of the semi-IPN hydrogel, the cellulose or its derivative is linear or branched in a crosslinked network (Nakayama et al. 2004).

\section{Cellulose-inorganic hybrid hydrogels}

Cellulose-inorganic hybrid hydrogels are designed by incorporating inorganic contents into CB hydrogel system to improve functional performance. Recently, these types of hydrogels have become the focal point for their promising applications in electric, optical, magnetic and biological fields (Chang and Zhang 2011; Nie et al. 2005). Kumar et al.(2017) prepared cellulose-inorganic hydride hydrogel from cellulose nanocrystals by reinforcing with polyacrylamide/sodium alginate/silica glass, which showed improved mechanical properties in terms of good compressive stiffness together with high porosity, interconnected pore structure, high degradation stability, thermal stability, good cell adhesion and proliferation making them suitable for bone tissue engineering applications. Besides, the biomineralized thermo-responsive injectable hydrogel was developed by block copolymerization of hyaluronic acid (HA) and poloxamer (obtained from poly(ethylene oxide)/poly(propylene oxide)/poly(ethylene oxide) (Huh et al. 2015).

\section{Principal properties of hydrogels}

\section{Swelling properties}

The swelling mechanism of hydrogels explains the swelling behavior and underlying reasons for retaining three-dimensional structure in solvent system. Hydrogels containing hydrophilic group(s) and the dissociated sodium carboxylate group increase osmotic pressure in the gel that leads to swelling of hydrogels. Repulsion between negative charges positively influences swelling by expanding polymer coils. On the other hand, crosslinked polymers in hydrogels do not let the solvent or water dissolve hydrogels and thus prevent infinite swelling as in Fig. 6 (Gooch 2011).

The factors on which swelling property and the degree of swelling depend on include network density, solvent nature, polymer solvent interaction parameter (Jin and Dijkstra 2010). Water or solvent appears as a plasticizer in a hydrophilic polymer network system. Swelling properties of hydrogels are elucidated by Flory-Rehner theory, 
Fig. 3 Chemical structure of a cellulose, $\mathbf{b}$ chitin and $\mathbf{c}$ chitosan polymer

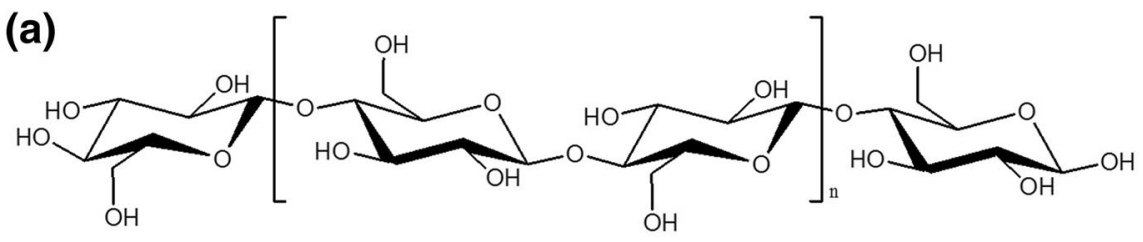

(b)

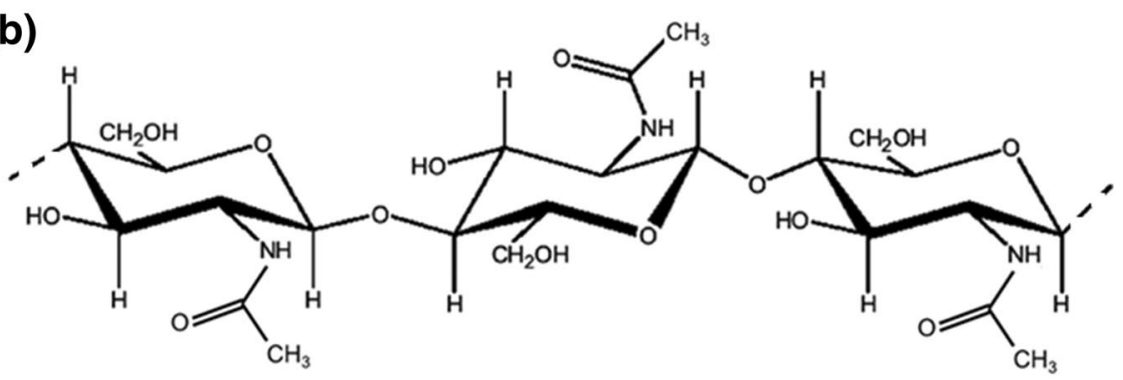

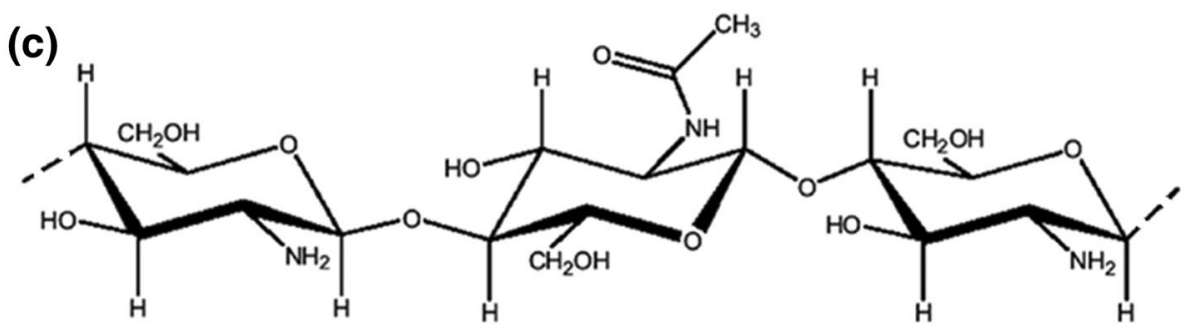

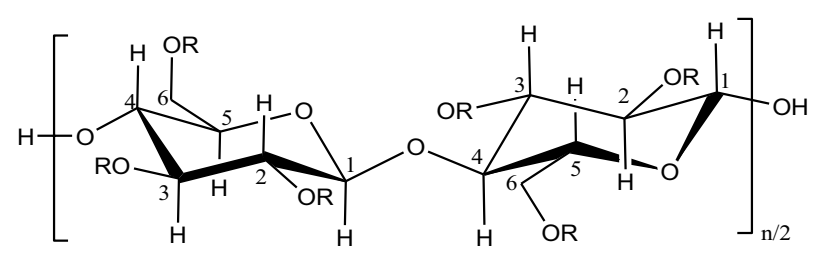

Cellulose ethers

Methylcellulose

Ethylcellulose

Hydroxyethyl methylcellulose

Hydroxypropyl cellulose

Carboxymethyl cellolose

Fig. 4 Chemical structure of ether derivatives

equilibrium swelling theory, using Gibbs free energy as follows (Koetting et al. 2015).

$\Delta G_{\mathrm{total}}=\Delta G_{\mathrm{mix}}+\Delta G_{\mathrm{el}}$

where, $\Delta G_{\text {total }}$ is the total free energy of the polymer network, $\Delta G_{\text {mix }}$ is the free energy contributions due to enthalpy of mixing, and $\Delta G_{\mathrm{el}}$ is the free energy contribution due to the elastic retractile forces in the network. Initially, $\Delta G_{\text {mix }}$ has high negative magnitude $\left(\Delta G_{\text {mix }} \ll 0\right)$, but $\Delta G_{\mathrm{el}}$ is positive with a lower magnitude than $\Delta G_{\text {mix }}\left(\Delta G_{\mathrm{el}}>0\right)$. Therefore, their resultant effect is negative $\left(\Delta G_{\mathrm{mix}}+\Delta G_{\mathrm{el}}<0\right)$. At this stage, swelling starts and diffusion of solvent occurs into the network. During swelling, both are increased until their magnitude becomes zero, $\left|\Delta G_{\text {mix }}\right|=\left|\Delta G_{\text {el }}\right|$, so that the total free energy become zero, $\Delta G_{\text {total }}=\Delta G_{\text {mix }}+\Delta G_{\mathrm{el}}=0$. Under this circumstance, there is no driving force for swelling, meaning that swelling stops and thus equilibrium of swelling is achieved (Yang 2012).

\section{Mechanical properties}

To explain mechanical behaviors of hydrogels, rubber elastic theory is regarded as the most efficient approach, because it associates important bulk property of hydrogels: rubbery modulus scales, temperature, and crosslinking density (De Gennes 1979; Flory and Rehner 1943; James and Guth 1943; Wall 1942). Hydrogels show elastic property like rubber; however, original rubber theory cannot properly explain the nature of hydrogels in aqueous medium and demands some modifications (Chai et al. 2017). Later, Peppas et al. (2000) developed an Eq. (2) being known as rubber elastic theory is given below, which may describe the structure of hydrogels in solvent.

$\tau=\frac{\rho \mathrm{RT}}{\mathrm{Mc}}\left(1-\frac{2 \mathrm{Mc}}{\mathrm{Mn}}\right)\left(\alpha-\frac{1}{\alpha^{2}}\right) \sqrt[3]{\left(\frac{v_{2, \mathrm{~s}}}{v_{2, \mathrm{r}}}\right)}$

Here, $\tau$ is the applied stress to the polymer as a function of elongation, $\rho$ is the polymer density, $R$ is the universal 
Fig. 5 Chemical structure of cellulose ester derivatives

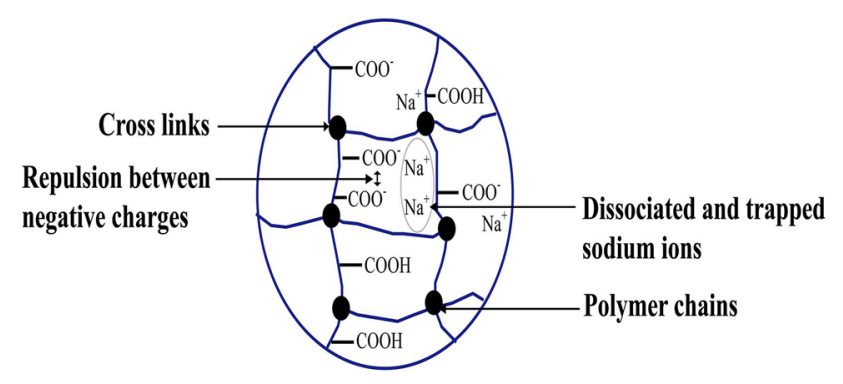

Fig. 6 Swelling mechanism of hydrogels. Reproduced from Gooch (2011) with permission from the Springer Nature

gas constant, $T$ is the absolute temperature, and $M_{\mathrm{c}}$ and $M_{\mathrm{n}}$ are the average molecular weights between and without crosslinks, respectively, $\alpha$ is known as the extension ratio, and $v_{2, \mathrm{~s}}$ and $v_{2, \mathrm{r}}$ are the polymer volume fraction in the swollen and relaxed states (Koetting et al. 2015).

\section{Applications of cellulose-based hydrogels}

\section{Biomedical applications}

Hydrogels are one of the most prominent classes of polymers convenient to be employed in biomedical fields. Hydrogels possess diverse properties with biocompatibility and resemblance to living tissue that allows ample opportunities for biomedical applications, particularly in drug delivery and release systems, wound dressings as well as tissue engineering (Caló and Khutoryanskiy 2015).

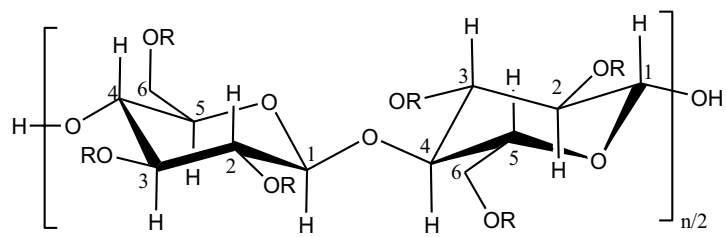

R groups

$\mathrm{H}, \mathrm{I}$

H, I, II

I, III

$\mathrm{H}, \mathrm{CH}_{3}, \mathrm{CH}_{2} \mathrm{CH}(\mathrm{OH}) \mathrm{CH}_{3}$, III, IV

$\mathrm{H}, \mathrm{CH}_{3}, \mathrm{CH}_{2} \mathrm{CH}(\mathrm{OH}) \mathrm{CH}_{3}$, III, V<smiles>CC(=O)c1ccccc1C(=O)O</smiles>

III<smiles>CCC(C)OC(=O)c1ccccc1C(=O)O</smiles>

IV<smiles>CC(=O)CCC(=O)O</smiles>

V

\section{Drug delivery}

Drug release system using hydrogels function by the delivery of drugs at desired locations (tissue, cells) in response to environmental stimuli such as light, temperature, $\mathrm{pH}$, chemicalactions,electric and magnetic fields. The polymeric aggregation due to swelling and shrinking property of hydrogels causes the change in transmittance, hydrodynamic radius, and stimuli-induced intermolecular and intramolecular hydrogen bonding (Qiu and $\mathrm{Hu}$ 2013). As a result, the drugs loaded in the assembly could be released, while disassembling occurs followed by swelling to loosen the hydrogel structures because of the actions of proximate stimuli (Qiu and $\mathrm{Hu}$ 2013). Moreover, swelling also affects the response rate, since it has a significant effect on the composition of hydrogels (Caykara et al. 2006). Stimulus-response rate is promoted and retarded due to swelling and shrinking, respectively. Amazingly, the inclusion of cellulose and its derivatives at various reaction levels leads to structural and morphological changes in hydrogel system in terms of enhancement of pore sizes due to repulsive forces of intra carboxyl groups directing to a large swelling ratio (Chen et al. 2010; Ciolacu et al. 2012). Thus, cellulose incorporation in hydrogels makes them an appropriate candidate for a manageable drug release. Also, the beauty of CB hydrogels is their biocompatibility, which has been verified by viability test (Tan et al. 2011; Xu et al. 2010).

There are numerous research articles along with critical reviews (Caló and Khutoryanskiy 2015; De las Heras Alarcón et al. 2005; Deligkaris et al. 2010; Elbert 2011; Gaharwar et al. 2014; Hoffman 2001; Hoffman 2012; Hoffman 2013; Kashyap et al. 2005; Klouda and Mikos 2008; Li et al. 2012; Mano 2008; Peppas 1987; Satarkar et al. 2010; Seliktar 2012; Tomatsu et al. 2011; Van der Linden 
et al. 2003; Ward and Georgiou 2011) and books (Andrade 1976; Gerlach and Arndt 2009; Ratner and Hoffman 1976) on the biomedical applications of hydrogels with an special emphasis on controlled drug delivery. A recently published review article piles up studies dedicated solely to drug delivery perspective of biodegradable hydrogels based on chitosan, poly(lactic-co-glycolic acid) and bacterial cellulose (Villalba-Rodríguez et al. 2017). Temperature, $\mathrm{pH}$ and redox-sensitive hydrogels are mostly useful for drug delivery because the body's biological mechanisms are mostly connected with these stimuli. For example, the development of $\mathrm{pH}$-responsive carboxymethyl cellulose (CMC) based hydrogel membrane crosslinked with acrylateis initiated for drug release and wound dressing applications (Pal et al. 2006). Thermo-sensitive volumetric nature of hydroxypropyl cellulose (HPC) and poly ( $N$-isopropylacrylamide) (PNIPA) hydrogels are identified for biomedical applications (Marsano et al. 2004). Thiolated hydroxypropyl cellulose as redox and temperature sensitive hydrogel for controlled drug delivery and smart materials has been proposed by Tan et al. (2011). Oral drug release application using $\mathrm{pH} /$ temperature sensitive CB hydrogel from phyllostachys heterocycla is anticipated by Zhou et al. (2014). In addition, Bai et al. (2012) designed pH and thermo-responsive hydrogel from emulsion polymerization of poly (L-glutamic acid-2-hydroxylethyl methacrylate) (PGH) and hydroxypropyl cellulose-acrylic acid (HPC-AA) for a managed delivery of oral insulin.

Controlled release of other proteins including dextran, ketoprofen, bovine serum albumin (BSA) and alaptide have been reported by some studies through the development of IPN and semi-IPN HPC-PAA, polyacrylamide-graftedxanthan (PAAm-g-XG) and other CB hydrogels (methylcellulose, hydroxyethyl cellulose and hydroxypropyl cellulose), respectively (Chen and Fan 2008; Kulkarni and Sa 2008; Sklenář et al. 2013; Xu et al. 2010). Dutta et al. (2016) have prepared two types of triple ( $\mathrm{pH}$, temperature and redox) stimuli responsive hydrogels from carboxymethyl cellulose (CMC) and poly( $N$-isopropylacrylamide), where one is prepared by copolymerization (copolymerizing $\mathrm{N}$-isopropylacrylamide) and the other one, methacrylated carboxymethyl cellulose, is by polymerizing NIPA in the presence of CMC. To make them redox responsive, two types of redox responsive crosslinkers $\left(N, N^{\prime}\right.$-methylenebisacrylamide (BIS) and $N, N^{\prime}$-bis (acryloyl) cystamine (BAC)) are used. BAC crosslinked polymer is found to have higher swelling property than BIS crosslinked one, and lysozyme loaded in the hydrogels is released manageably through controlling temperature, $\mathrm{pH}$ and glutathione as a reducing agent. Besides, the release of BSAis marked by superabsorbent CB hydrogels (CMC and cellulose in the $\mathrm{NaOH} /$ urea aqueous system crosslinked with epichlorohydrin (ECH)) through shrinking and swelling mechanism (Chang et al. 2010). The drug loading procedure in the presence of crosslinking agent is presented in Fig. 7a, and drug control release mechanism of a temperature responsive hydrogels that swells and releases drug based on a set temperature and vice versa (Fig. 7b).

Target drug release is another crucial aspect of drug delivery for a precise and desired demonstration. Shen et al. (Shen et al. 2016) summarized drug release applications of stimuli-responsive CB hydrogels (cellulose/CMC and cellulose/lignin crosslinked with $\mathrm{ECH}$, and cellulose/cellulose nanowhisker $(\mathrm{CNW})$ ) that are sensitive to chemical species (Ciolacu et al. 2012; Wang and Chen 2011; Xu et al. 2010), $\mathrm{pH}$ (chitosan/alginate crosslinked with $\mathrm{Ca} 2+/$ tripolyphosphate (TPP), chitosan/pectin crosslinked with $\mathrm{Ca}^{2+}$ and $\mathrm{SO}_{4}{ }^{2-}$, cellulose/PAAm, or PAAc crosslinked with $N, N^{\prime}-$ methylenebisacrylamide (MBAAm)) (Anal and Stevens 2005; Bigucci et al. 2008; Chang and Lin 2000; Xu et al. 2007), magnetic field (cellulose/ $\mathrm{Fe}_{3} \mathrm{O}_{4}$ glutaraldehyde (GA)), injectable (chitosan/CMC, chitosan/collagen, chitosan/polyethylene glycol (PEG)) (Bhattarai et al. 2005; Chen and Fan 2008; Chiu and Radisic 2011), temperature (cellulose/ PNIPAAm crosslinked with MBAAm, cellulose/poly $(N$ vinylcaprolactam) (PNVCL) crosslinked with MBAAm, chitosan/PNIPAAm crosslinked with MBAAm and GA, chitosan/PNVCL) (Alvarez-Lorenzo et al. 2005; Montes et al. 2015; Sanna et al. 2013; Wang et al. 2013). Among these hydrogels, CB hydrogels facilitate a desired delivery of drugs at around neutral medium, whereas chitosan-based hydrogelsare at a lower $\mathrm{pH}$ medium. The base whether pure
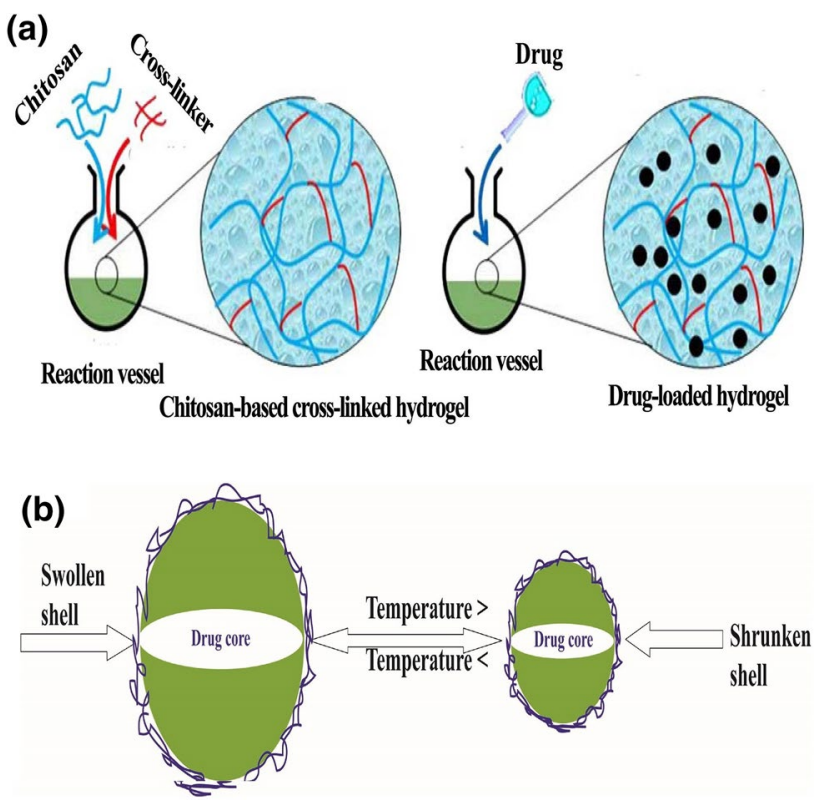

Fig. 7 Schematic diagram of a loading of drug in the chitosan-based hydrogel structure during crosslinking reproduced from Villalba-Rodríguez et al. (2017) and $\mathbf{b}$ a temperature responsive hydrogels as controlled drug carriers 
cellulose or chitosan-based hydrogel to be used is defined by some criteria such as $\mathrm{pH}$, temperature and chemical species. Because, for example, $\mathrm{pH}$ of different organs of human body are different and ranges from 1 to 7.5 (e.g., saliva 5-6, stomach 1-3, intestine 6.6-7.5, and colon 6.4-7.0) (Bhattarai et al. 2010).

On the other hand, Feketeet al. (2017) mentioned that carboxymethyl cellulose/starch superabsorbent hydrogels prepared by gamma-irradiation works better than pure CB hydrogel in the context of a higher water uptake at a higher electrolyte concentration. Chitosan/pectin hydrogels are responsible for colon-specific delivery for their mucoadhesion characteristics and enzyme-dependent degradation. Again, $\mathrm{pH}$ sensitive hydrogels can be assigned as prospective oral drug carriers for intestine or colon-specific delivery. They offer target drug carriers without employing invasive surgeries leading to extending release time and encapsulating drugs. Ahmadi et al. (2015) mentioned multi-dimensional drug delivery system of chitosan-based hydrogels for oral, ocular and nasal drug delivery. For dermal and transdermal drug delivery systems, use of cellulose-derivativesbased hydrogels have been elucidated by Vlaia et al. (2016). Target protein delivery using $\mathrm{Fe}_{3} \mathrm{O}_{4}$ nanoparticles in the regenerated cellulose microspheres is developed by establishing magnetic-induced transference (Luo et al. 2009).

Cellulose-based hydrogels hold a great promise for technological advances in the early detection and treatment of diseases. Nanoparticles like lipid-based micelles and liposomes, polymeric micelles and dendrimers, carbon nanomaterials, and inorganic and metallic nanoparticles are being used for numerous applications such as site-specific drug delivery, biosensors for in vitro and in vivo diagnostics and contrast agents for medical imaging (Roman 2017). Cellulose derivatives are also used to meet different requirements such as fillers, solubility and bioavailability enhancers of active pharmaceutical ingredients, to ease manufacturing of dosage forms or to achieve a certain release profile from formulations (Grace Okoh 2017).

\section{Wound healing}

Wound healing is a natural restorative response that can be used to fix the damaged tissues. Healing is the interaction of a complex cascade of cellular events that generate resurfacing, reconstitution and restoration of the tensile strength of injured skin (Patrick et al. 2016). It is also a complex and dynamic process of replacing devitalized and missing cellular structures and tissue layer (Michael Mercandetti 2017). CB hydrogels and their derivatives are commercially available as wound dressing products in different forms such as fibers, membranes and sponges (Jayakumar et al. 2011; Nagahama et al. 2008). The main reason is that deacetylated chitin or chitosan is a hemostat and polycationic in nature, so it possesses a natural antimicrobial property (McCarthy et al. 2005). Usually, cellulose itself has no antimicrobial activity to prevent wound infection and thus $\mathrm{ZnO}$ or $\mathrm{Ag}$ nanoparticles (NPs) are impregnated into the cellulose gel system to confer antimicrobial properties (Katepetch et al. 2013; Li et al. 2011; Maneerung et al. 2008). However, chitin and chitosan possess hemostatic, antimicrobial and permeable properties, therefore, dressing materials made of those polymers are non-irritating and non-allergic (James and Guth 1943; Khan et al. 2000; Mi et al. 2001). The porous and the interconnected 3D structures of hydrogels aid the growth of the cells, also the easy modification of the polymers allows them to act as strong and multipurpose carriers for drug conveyance. Nowadays, novel injectable hydrogels can substitute risky surgeries (Shamma et al. 2017).

Chitosan derivatives exhibit an enhanced bacteriostatic activity compared to pure chitosan and show few interesting properties in self-healing applications (Prabaharan and Mano 2006). In addition, recent applications are associated with various types of 'intelligent' self-healing and anticorrosion coatings that use the stimuli-responsive behavior of polymer-based nanoparticles (Motornov et al. 2010). Yang and Lin (2004) developed temperature-responsive wound dressing materials from polypropylene nonwoven fabric (PP) and acrylic acid (AA) by $\gamma$-irradiation-induced method to achieve PP- $g$-AA and modified by $N$-isopropylacrylamide (NIPAAm) through graft-copolymerization along with ultraviolet photografting to achieve PP- $g$-AA- $g$-NIPAAm bigraft nonwoven fabric. Then chitosan was impregnated onto (PP)$g$-AA- $g$-PNIPAAm bigraft nonwoven fabric material. Their research finds the evolution of relative wicking time and the antibacterial assessment on the dressing materials. The relative wicking time was found to decrease for the PP- $g$-AA$g$-PNIPAAm-chitosan. Studies on the transport of bacterial and water vapor transmission rates (WVTR), the permeance and the permeability through the modified nonwoven fabric, have also been conducted. As pure PP is porous, it shows the highest values of WVTR and permeance. After some changes, the PP- $g$-AA- $g$-PNIPAAm forms a dense cross-section, so the permeance and permeability values of WVTRdrop sharply. Relative wicking time of PP- $g$-AA$g$-PNIPAAm increases with increasing the temperature and then levels off for temperatures above $328{ }^{\circ} \mathrm{C}$ due to the thermo-sensitive behavior of the PNIPAAm. Since chitosan is a cationic polysaccharide and the bacterial cell surfaces are negatively charged, the adsorption of the negatively charged cell surfaces onto the nonwoven fabric increases with increasing the charge density on the chitosan containing $\mathrm{PP}-\mathrm{g}$-AA, resulting in a decrease in the viable cell number. The modified nonwoven fabric with chitosan can be considered for wound dressing, as the values of WVTR, permeance and permeability of the PP- $g$-AA- $g$-PNIPAAm-chitosan 
are comparable to the commercial products (Yang and Lin 2004).

\section{Tissue engineering}

Tissue engineering refers to the most recent applications of CB hydrogels, in which they work as scaffolds to mimic cellular functions of extracellular matrixes and to engender new tissues (Radhakrishnan et al. 2015). For example, scaffolds provide proper conditions (space and nutrients) for a desired new tissue generation and potentially regulate the structure and function of the engineered tissue in situ or in vitro (Lee and Mooney 2001; Shen et al. 2016). In addition, hydrogel scaffolds are at near clinical uses in engineering many tissues in the body including cartilages, bones, muscles, skins, fats, arteries, ligaments, tendons, livers, bladders and neurons (Marler et al. 1998). Apart from clinical usage, hydrogel can be used as surface modification in tissue growth. Synthetic materials working as biomedical implants/supports for tissue growth require surfaces that either resist attachment of certain cells while binding others or being capable of binding a biological moiety under some conditions (Okano et al. 1995). This surface modification method can be a good option to control and modulate cellular interaction through preventing the adhesion of unwanted cells and promoting interaction between bone and skin with implant biomaterials. Applications define whether the surface of a biomaterial should promote cell adhesion or avoid the attachment of specific proteins and cells (Tallawi et al. 2015). Okano and co-workers (Harimoto et al. 2003; Shimizu et al. 2003; Shiroyanagi et al. 2003; Yamato et al. 2002; Yamato et al. 2001) have extensively used thermoresponsive PNIPAAm-based polymers as surface mediators of biopolymer and cell attachment. Tissue engineering also focuses on the replacement of damaged or infected tissues or organs that helps the body regenerate new functional tissues (Prabaharan and Mano 2006). According to Prabaharan et al. (2006), this is usually achieved through constructs containing living cells, a three-dimensional porous matrix or scaffold, and bioactive molecules. The formation should accelerate cell attachment, proliferation and differentiation. The scaffold materials should have an extensive set of properties such as biocompatibility, biodegradability, mechanical strength, porosity, potential of entrapment and release of pharmaceutically active agents.

Thermo-responsive hydrogels (i.e., chitosan- $g$-PNIPAAm) are good solution to avoid the challenges in mesenchymal stem cells (MSCs) culture. An et al. (2001) discussed various challenges facing culture of MSCs. The most visible drawback arises upon building MSC from the cell culture carrier because of high adhesive nature of MSC that involves application of harsh conditions. Therefore, a further study is required regarding cell culture carrier materials and gentle harvesting of the cultured cells. One method is the use of thermo-responsive hydrogels as cell culture carrier. By using thermo-responsive hydrogels, the cultured cells can be reformed by simply decreasing the temperatures below their lower critical solution temperature. Chitosan- $g$-PNIPAAm has decent characteristics for cellular attachment, proliferation and viability as well as differentiation into chondrocytes (An et al. 2001; Chenite et al. 2000). Due to these properties, an injectable gel material based on chitosan/PNIPAAm has been developed for chondrogenic differentiation of human MSCs and evaluation of cartilage formation in vivo after injecting a cell-thermo-sensitive gel complex (Gil and Hudson 2004). A further experiment on animal is performed to assess the cartilage formation in the submucosal layer of the bladder of rabbits. The thermo-sensitive gels system is opposite to in vivo applications, because its lower critical solution temperature (LCST) is $3200{ }^{\circ} \mathrm{C}$. As a result, this new combination (chondrogenic differentiated cells from MSCs with a thermo-sensitive polymer) is suggested to use as an injectable cell-polymer complex. Chondrogenic differentiation is found to be induced from the MSCs both in vitro and in vivo applications. The gel is recommended for obtaining an easy method for treating vesicoureteral reflux via an endoscopic single injection technique (without a dual injection system) (Cho et al. 2004).

\section{Smart materials}

CB hydrogels have been gaining popularity in fabrication of smart devices because of their overall biocompatibility, high storage capacity for cells and small molecules and low interfacial tension at the gel-aqueous solution interface (Tokarev and Minko 2009). Smart device like biochemical sensor translates chemical coding that includes the concentration of a specific sample component to a total composition analysis. Chemical sensors usually have two basic components connected in series: a chemical (molecular) recognition system (receptor) and a physio-chemical transducer. Biosensors are chemical sensors in which the recognition system utilizes a biochemical mechanism (Thévenot et al. 2001). Smart materials based on cellulose has unique properties such as strong mechanical strength, and biocompatibility, thus studies on 'smart' materials based on cellulose have been abuzz during the last decade (Qiu and Hu 2013). Cellulose particles, their derivatives and composites are abundant in nature with their various eco-friendly applications. They possess cellulosic properties and are used in electro-responsive electrorheological (ER) suspensions (Choi et al. 2017). Cellulose composite particles with carbon nanotube have extensive applications in conductors, wearable electronics, structure health monitoring, smart textiles, detection of liquids (such as water) leakages, strain sensor, thermistor, humidity or 
vapor sensors, strain sensor, biosensor, chemical sensors (gases or vapors), batteries, energy storage and supercapacitors (Qi 2017).

Stimuli-responsive polymer systems accelerate an efficient transduction mechanism that helps to prepare them suitable for use in sensor applications. Hydrogel film can be used as a highly sensitive $\mathrm{pH}$-responsive nano-sensor with short response times (Tokareva et al. 2004). According to Guenther and Gerlach (2009), a quick expanding field of on-line process monitoring for biotechnology, food industry, the pharmaceutical industry, process chemistry, environmental measuring technology, water treatment and sewage processing requires the development of new microfabricated reliable chemical biosensors that can process analytic information in a faster, simpler and economical manner. Biosensors being coated with functionalized hydrogels can detect transmit and record the information regarding the concentration change, the presence of specific functional groups or data by producing a signal. This signal is proportional to the concentration of the target analyte containing organic and inorganic contaminants (Guenther and Gerlach 2009). The sensitivity of hydrogels depends on a large number of physical factors such as temperature (Kuckling et al. 2003; Richter et al. 2004), electrical voltage (Richter et al. 2003), pH (Kuckling et al. 2003), concentration of organic compounds in water (Kumar et al. 2006) and salt concentration (Liu et al. 2003). Stimuli-responsive hydrogels are capable of reversibly converting chemical energy into mechanical energy that makes them very useful as a sensitive material for sensor applications. The following principles have been explored by Guenther and Gerlac (2009) for measuring the environmental parameters used in sensors based on the swelling behavior of hydrogels including modification of the holographic diffraction with respect to wavelength in optical Bragg-grating sensors, shifts of the resonance frequency of a quartz crystal microbalance in microgravimetric sensors, bending of micromechanical bilayer cantilevers and deflection of a membrane or bending plate 1 in capacitor/inductor micro-machined resonator and in piezo-resistive pressure sensors.

The swelling properties of $\mathrm{pH}$-sensitive hydrogels vary based on functional acidic or basic groups in the polymer backbone. The density of ions in the hydrogel is higher than that in the surrounding solution because of dissociation of these groups and the influx of counterions. This leads to a difference in osmotic pressure and solution flux into the hydrogel as well as in swelling properties. The interaction and repulsion of charges along with the polymer chain also cause to an increased swelling. Apart from sensitivity of $\mathrm{pH}$ and chemical composition, signal reproducibility and longterm stability are the most crucial aspects for a successful sensor implementation. The excellent long-term stability of the sensor is governed by the stability of the hydrogels.
The polymer film preparation and measurement conditions have been determined, which are necessary for a high signal reproducibility and high long-term stable sensor sensitivity. In order to provide the required high signal reproducibility of the sensors, two procedures were employed to run the process: (i) an initial gel conditioning procedure consisting of a gel swelling in de-ionized water and a subsequent deswelling/swelling cycling and (ii) a regenerating procedure prior to every measurement in order to achieve a certain reference sensor signal. In deeper sense, stimuli-responsive polymergrafted membranes can change their pore sizes through swelling and shrinking in response to external stimuli. These regulated membranes are designed to separate membranes and sensors (Qiu and $\mathrm{Hu}$ 2013). Recently, Richter (2010) has found that $\mathrm{CB}$ hydrogels follow this design principle in microfluidics and special imaging systems. Automatic microfluidic systems based on the sensor-actuator properties of hydrogels offer functionalities, which have not yet been realized with other systems or actuators. The author also shows the basic principles applied to an electronic control for hydrogel actuators and also to the basic components for microfluidics: microvalve, micropump and hydrodynamic transistors.

\section{Healthcare and hygienic products}

History reveals that the application of hydrogels as SAPs in the realm of personal healthcare and hygienic feminine products is quite phenomenal. The insoluble hydrogels by nature have a high liquid absorption capacity, which is one of the crucial requirements of SAP that can absorb water 1000 times of their initial dry weight. Their exceptional swelling property also assists to enlarge the pore size so that a large amount of secreted liquids like blood, urine can be engrossed in the hydrogel structure (Zohuriaan-Mehr and Kabiri 2008). Subsequently, hydrogels are widely applied for designing disposable diapers, napkins, adult urinary incontinence products and personal safety products (Klinpituksa and Kosaiyakanon 2017). Besides, SAPs showed a better performance than multilayered diapers and synthetic over pants providing protection against diaper rash, spreading germs, leakage of diapers for minimizing fecal contamination, gastrointestinal illnesses (Adalat et al. 2007; Holaday et al. 1995).

Despite the use SAP for the personal disposable purpose, it is first patented in 1972 (Atkins et al. 1972; Harmon 1972), the commercial use of SAP as sanitary napkins came into existence in 1982, which was introduced by Unicharm Japan. In their invention, they embed superabsorbent polymer in layer by layer form between the top and bottom sheet of the diaper/napkin system (Fig. 8). This revolutionary innovation has earned tremendous popularity throughout the globe due to its extraordinary liquid retention power 


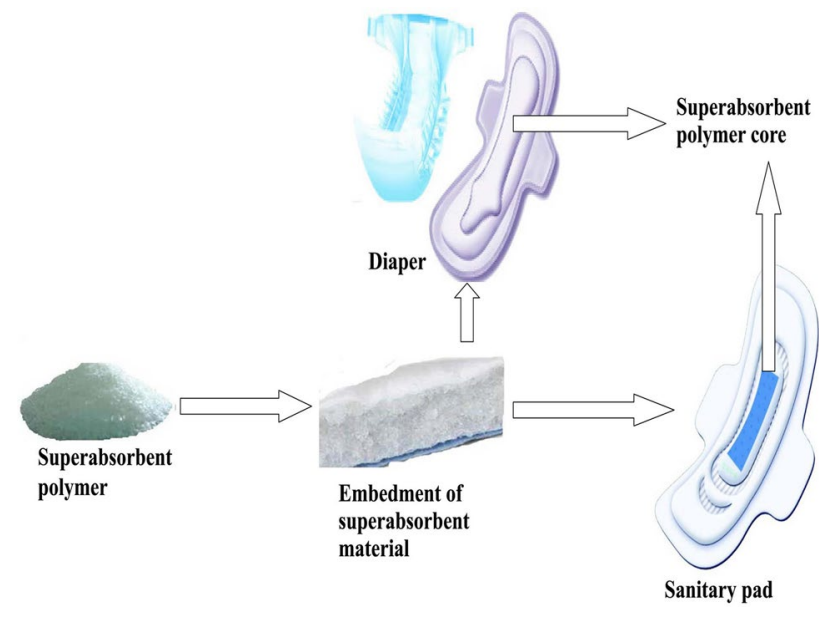

Fig. 8 Super absorbent polymer embedment in diaper/napkin system

with reduced diaper rash and leakage risk (Sannino et al. 2009). Nowadays, more than $90 \%$ of the diapers, napkins and other hygiene products are made of synthetic polymers mostly based on acrylate such as acrylic acid or acrylamide (Friedrich 2012). Some obvious drawbacks associated with synthetic SAHs include toxicity, non-biodegradability, expensiveness, environmental unfriendliness and huge waste load after disposal (Ma et al. 2015). Later, with the development of SAH from flax yarn waste overcomes the limitations of the traditional synthetic hydrogels (Liu et al. 2014). Besides, CB hydrogels such as CMC and hydroxyethyl cellulose (HEC) crosslinked with divinyl sulphone show improved swelling property and a higher water uptake percentage under centrifugal loads compared to their synthetic counter parts and thus turn out to be a suitable alternative tothe synthetic SAHs (Sannino et al. 2004).

Seki et al. (Seki et al. 2014) introduced CMC and HEC based hydrogels responsive to $\mathrm{pH}$ and salt. They assessed the water absorption capacity and tensile strength of the newly developed hydrogels at different $\mathrm{pH}$ and salt concentrations and showed that water absorption is higher at neutral $\mathrm{pH}$ (7.4) and becomes lower with decreasing charge of metal ion of salt. Besides, the incorporation of microporous structure in the hydrogels through phase inversion desiccation technique in the presence of acetone results in an enhancement of water retention and swelling kinetics due to capillary effects (Onofrei and Filimon 2016; Sannino et al. 2009). The development of biodegradable, renewable and recyclable CB hydrogels using non-toxic crosslinker such as, gamma irradiation crosslinking for the modernization of SAH in the domain of hygienic and personal healthcare products has been investigated in some contemporary research. Barleany et al. (2017) proposed that acrylic acid being neutralized with $\mathrm{KOH}$ and mixed with chitosan to form superabsorbent poly(acrylic acid)-graft-chitosan hydrogel by gamma irradiation technique can improve water absorption capacity. Cellulose-based SAP through the inverse suspension polymerization, using cellulose, acrylic acid and acrylamide as monomers having humidity resistant property, and a higher water uptake capacity was prepared by Guan et al. (2017). In addition, Peng et al. (2016) proposed a novel CB hydrogel prepared by chemical crosslinking of quaternized cellulose (QC) and native cellulose in $\mathrm{NaOH} /$ urea aqueous solution in order to overcome some inherent weaknesses including poor mechanical property, inferior biocompatibility as well as lack of antimicrobial activity associated with the existing SAHs employed in commercial disposable diapers.

\section{Agricultural use}

In agriculture, proper irrigation and supply of nutrients are pressing needs for a favorable germination and upbringing of plants and crops (Ismail et al. 2013). Hydrogels of SAPs, alternatively SAHs, have been widely used during past five decades in various aspects of agricultural system including an enhancement of soil property (permeability, density, structure, texture, water evaporation, filtration rate) (El-Rehim et al. 2004), release and carry agrochemicals (Li et al. 2009b), assist in growing plant in both drought affected and arid areas (Woodhouse and Johnson 1991), stimulate sprouting (Knypl and Knypl 1993), rise nodulation between actinorhizal plant species (Kohls et al. 1999) as well as performing as soil additive (Lokhande and Varadarajan 1992). Moreover, SAHs can also be employed in cultivating artificial edible products (Zohuriaan-Mehr et al. 2010), ornamentation of plants (Abedi-Koupai and Asadkazemi 2006), developing properties of horticulture substrate (bark, perlite, peat, and their mixtures) (Martyn and Szot 2001), establishing biotechnical protection (Orzeszyna et al. 2006), promoting sand stabilization (Han et al. 2007; Jafarzadeh et al. 2005), motivating bacterial aggressiveness (Lee et al. 2008), control erosion, standing water and petroleum spills (Zohuriaan-Mehr et al. 2010). All these agricultural and horticultural applications of SAHs can be categorized under two broad segments namely; water reservoir and nutrient carrier.

The soil is extensively arid in the drought-affected regions of the world such as Africa, South America, east of Asia, which poses a great threat to the plants/crops (Ma et al. 2015). SAHs have gained much popularity for the application in that regions through eliminations the soil aridity via moisturizing as well as improving water retaining capacity of the soil for an extended period of time (Guilherme et al. 2015). After mixing the soil with hydrogels, a huge amount of water is stored by swelling of hydrogels upon watering either naturally or by irrigation. This phenomenon enables soil particles to turn from glassy to rubbery state even under compressive force. On the other hand, releasing occurs very slowly through the diffusion-driven mechanism in the 
presence of humidity gradient developed between the outside and inside of the hydrogels (Ma et al. 2015). Therefore, a large amount of water is retained in the hydrogel structure that eventually releases slowly when required (Fig. 9). This process also decreases the frequency of irrigation and thus reduces a significant amount of water that could serve other purposes. At the same time, it also saves the reserved water in the hydrogel from evaporation and drainage. Another interesting thing worthy to be noted is due to swelling effect, hydrogel granules being almost similar in size to other particles in the dry state get bigger upon absorbing water. As a result, the compact hydrogel-soil interaction becomes loose that ultimately causes more oxygenation and growth of plant root by increasing soil porosity (Sannino et al. 2009).

Nowadays, essential and compatible nutrients are fabricated with hydrogels and applied altogether during cultivation. Loading stimulus-responsive hydrogels, functional services of hydrogels can be improved with respect to the controlled release of agrochemicals (drugs, herbicides or pesticides). These conglomerations mitigate environmental pollution due to agrochemicals and also ensure smooth and continuous supply of those chemicals to the plants, because they are already retained in the hydrogel structure (Ismail et al. 2013). As mentioned earlier, most of the SAHs being used today are synthetic hydrogels (mostly acrylate-based), making themselves as soil pollutant because of their nonbiodegradable nature. CB hydrogels are thus of great interest in academic and industrial research due to their environmentally friendly nature in terms of biodegradability, renewability, non-toxicity, non-petrochemical property. Cellulose-based hydrogels from chitosan, CMC, starch and other polysaccharides have been used to optimize water reservoir (Cannazza et al. 2014; Demitri et al. 2013; Montesano et al. 2015; Sánchez-Orozco et al. 2017). The use of hydrogel from $\mathrm{CMC}$ is also found suitable for a controlled release of herbicide like acetochlor based on diffusion mechanism

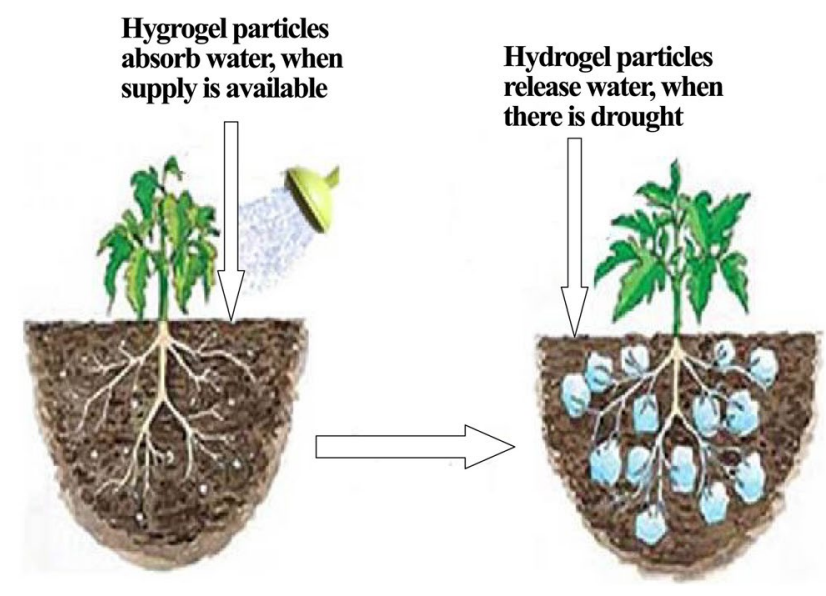

Fig. 9 Change of soil porosity with the swelling of hydrogels
(Li et al. 2009a; Li et al. 2008). Cellulose from palm oil-free fruit bunch along with polyacrylic acid hydrogels is found to improve soil-retaining capacity and urea leaching loss rate of sandy soil (Laftah and Hashim 2013). Hydrogels made of polyacrylamide (PAAm), methylcellulose and calcic montmorillonite have been proved to impart controlled release of fertilizer through volatilization of ammonia (Bortolin et al. 2013). Furthermore, to highlight applications of hydrogels as nutrient carriers, different types of CB hydrogels for releasing nutrients, acids, fertilizer, herbicide, urea etc. are summarized in a study (Guilherme et al. 2015). Hydrogel being synthesized from $\mathrm{CMC}$ and polyvinyl pyrrolidone (PVP) crosslinked with gamma irradiation finds versatile agricultural applications ranging from urea release to good water retention capacity (Wang and Wang 2010).

\section{Applications in textile processing}

Cellulose hydrogel materials have garnered much attention for application in the field of textiles including the processing of textile materials and treatment of textile wastewater through adsorption. Some of their exceptional properties namely high absorbency, porous structure, rich functional groups and relatively lower crystallinity (Shen et al. 2016; Tang et al. 2011; Zhou et al. 2005) have touted CB hydrogels as a potential candidate for the application in textile wet processing (dyeing and printing) (Hu et al. 2012), development of heat and moisture management textiles (Hu et al. 2012) as well as disposable absorbent personal-care products with self-fitting capability (Topolkaraev and Soerens 2003). Besides, hybrid hydrogels with the incorporation of different particles can be employed to remove various water pollutants resulting from the textile wastewater such as metal ions (transition or radioactive) (Fu and Wang 2011; Li et al. 2005; Ngah and Fatinathan 2010; Ngah et al. 2004), dyes (cationic or anionic), (Azlan et al. 2009; Copello et al. 2011) and other ions (nitrogenous or phosphorous) (Chatterjee and Woo 2009; Zheng and Wang 2009). At present, many liquid and solid-phase extraction techniques have been widely used for the removal of toxic pollutants from wastewater including chemical precipitation, flocculation, flotation, coagulation, membrane filtration, ion exchange, adsorption and electrochemical treatments ( $\mathrm{Fu}$ and Wang 2011; Shen et al. 2016). From a contemporary research, it has been revealed that cellulose hydrogels can also be employed efficiently to remove partially or fully dissolved pollutant substrates from wastewater by allowing them to penetrate deep into their structure and forming bonds with the pollutants through more reactive amine $\left(-\mathrm{NH}_{2}\right)$ and/or hydroxyl $(-\mathrm{OH})$ groups at their optimum $\mathrm{pH}$ values (Shen et al. 2016). The resulting bond formation occurs mostly due to three kinds of interactions that include complexation (or chelation) between the lone pair electrons of $\mathrm{N}$ and/or 
$\mathrm{O}$ and the metal ions ( $\mathrm{Li}$ and Bai 2005; Tang et al. 2011; Tang et al. 2014; Zhou et al. 2005), crystallization of the metal ions with the complexed metals as nucleation sites (Fu and Wang 2011; Sklenár et al. 2013; Zhou et al. 2005) and electrostatic attraction (or ion exchange) between the protonated amino groups and various anions (Chatterjee et al. 2010; Chatterjee and Woo 2009). The superabsorbent chitosan-starch hydrogel shows excellent swelling ability in both water and DR80 (dye) solutions. Chitosan-starch hydrogel is efficient for DR80 removal under batch system. For successful sorption, dissociation of DR80 dye molecules and activation of chitosan-starch hydrogel functional groups induce electrostatic force of attraction (Ngwabebhoh et al. 2016). The binding of DR80 dye molecules and chitosanstarch hydrogel surface are bonded as shown in Fig. 10.

\section{Miscellaneous applications}

SAHs based on cellulose also find themselves in a number of miscellaneous applications including construction purpose, electrical use, membrane and flocculant manufacturing, water swelling rubbers, artificial snow, packaging and re-freshening systems, enzyme and catalyst supports, fire-extinguishing gels, sludge/coal dewatering, body water retainers, stomach bulking agents and food preservatives (Zohuriaan-Mehr et al. 2010).

Constructional uses of SAHs mainly include preparation of cementation (Mignon et al. 2017b) and demolition of building structures (Ismail et al. 2013). Crack formation because of autogenous shrinkage, decreasing freeze/thawing and other constructional stresses are major concerns for building constructions. Synthetic SAHs have been successfully experimented to combat this problem through internal curing, self-sealing effect, autogenous healing (Mignon et al. 2017b). Kinetics and water release behavior of SAHs during cementations have been investigated recently by nuclear magnetic resonance (NMR) (Snoeck et al. 2017). However,

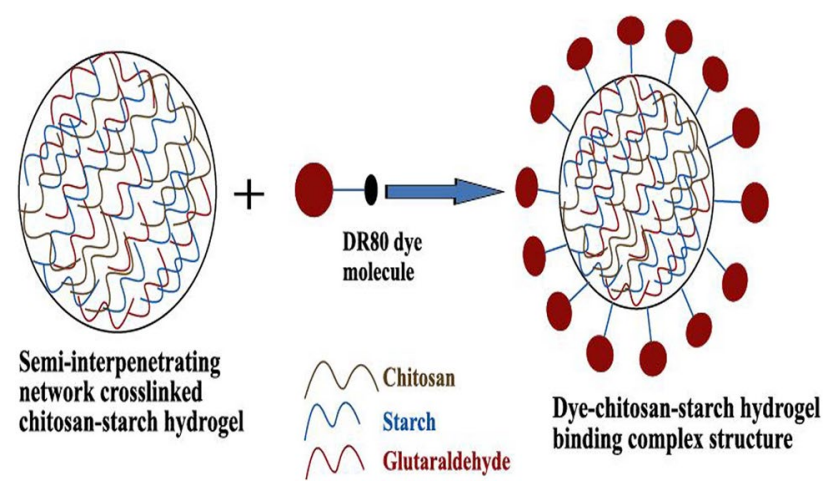

Fig. 10 Adsorption mechanism of DR80 dye onto chitosan-starch hydrogel surface (reproduced from Ngwabebhoh et al. (2016) with permission from the Elsevier) this approach of using synthetic SAHs has also some innate limitations such as formation of macropores that adversely affects the concrete strength (Gupta et al. 2017; Mechtcherine et al. 2017; Mignon et al. 2017b; Schröfl et al. 2017). Some recent works (Mignon et al. 2017a; Mignon et al. 2016; Mignon et al. 2017c; Mignon et al. 2017d; Schröfl et al. 2017) have suggested use of cellulose-based SAHs in mitigating the strength problem due to excessive swelling of synthetic SAHs. In contrast, the application for demolition is based on the opposite principle, using highly absorbing hydrogels (Ismail et al. 2013). Kobayashi et al. (1990) have patented acrylonitrile-graft-starch hydrogel as demolishing agent that swells upon contacting water and thereby weakens the rigid structures through expansion.

CB stimulus hydrogels are utilized for designing electric cables as water blockers (Ismail et al. 2013) and electroactive devices (electrolytes, sensor, actuators, robot haptics) (Cunha et al. 2017). Hydrogels from homo-polymers, copolymers and/or mixtures of sodium and potassium polyacrylates, partial sodium salts of polypropenoic acid and starch-grafted sodium polyacrylates are used for wrapping cables in order to prevent water penetration (Ismail et al. 2013). Cunha et al. (2017) introduced electrolytes being comprised of microcrystalline cellulose (MCC) in aqueous $\mathrm{LiOH} /$ urea solvent, where $\mathrm{CMC}$ is blended at different levels. This recyclable/disposable, biodegradable, eco-friendly cellulose electrolyte hydrogel has some improved features such as high specific capacitances, transparency and flexibility making it suitable for engineering many electrical devices (sensors, transistors). Physical crosslinking of polyvinyl alcohol and cellulose generates cellulose electroactive hydrogel for actuator applications (Jayaramudu et al. 2017). Besides, cellulose and its derivative (chitin/chitosan/PVA) hydrogel membranes containing ILs, $\mathrm{H}_{2} \mathrm{SO}_{4}, \mathrm{NH}_{4} \mathrm{NO}_{3}$ and ethylene carbonate are used for capacitor/battery (Shen et al. 2016).

Cellulose-based hydrogel system is also used as electrolyte membranes and flocculants. Hydrogel from chitosan crosslinked with polyacrylic acid has been used in the fuel cell as a membrane for facilitating ion exchange mechanism (Smitha et al. 2004). Navarra et al. (2015) prepared CB hydrogel crosslinked with epichlorohydrin for gel electrolyte membrane applications. Hydrogels are applied to ease water purification process; for example, hydrogel prepared from guar gum has been proposed for water separation from wastewater (oil-water) by coating stainless steel mesh to render an excellent underwater oleophobicity and super-low oil sticking. Flocculation is the phenomenon of precipitation in the form of small lumps due to chemical interactions between soil particles and others such as salt water depending on settling time, temperature, number of polymers and $\mathrm{pH}$ of the solution. Psyllium based hydrogels (methacrylic acid, polymethyl methacrylate grafted psyllium) can act as 
cheap and green flocculants. Cationized CMC treated with $\mathrm{N}$-(3-chloro-2-hydroxypropyl) trimethylammonium chloride (Hebeish et al. 2010) and hydroxypropyl methylcellulose grafted with polyacrylamide (Das et al. 2013) have been also found as outstanding flocculants in the light of the factors affecting flocculation efficacy.

Hydrogels by their nature exhibit crosslinking properties as explained by rubber elastic theory (Oyen 2014). Water swelling rubbers are like typical hydrogels used for construction applications as water blockers of underwater tunnels and subways so that water cannot pass through the structure in case of any leakage (Zohuriaan-Mehr et al. 2010). Hydrogel from natural rubbers comprising poly(ethyleneoxide) and glycidyl methacrylate (GMA) as a reactive coupling agent can be used as water swelling rubbers. Yang et al. (2013) prepared rubbery hydrogel by free radical polymerization of cellulose nanocrystals and polyacrylamide (without chemical cross-link) and analyzed network structure and mechanical properties that affirm that the prepared hydrogel can be applied in environmentally benign applications.

In addition, the materials used for packaging are mostly of synthetic nature and non-biodegradable. In this regard, CB hydrogels could offer a green solution to the packaging industry with enhanced mechanical strength. Roy et al. (2012) prepared hydrogel film from polyvinylpyrrolidone and CMC by solution casting method. The resulting new hydrogel film showed a better mechanical strength, biodegradability and ability to absorb moisture from fruits and vegetables. To augment hydrogel packaging system in terms of preserving food products, some successful efforts have been made by incorporating antimicrobial property that cannot only keep food safe and dry but also protect them from the attack of bacteria like Escherichia coli (E. coli). Strong antimicrobial hydrogel package could be made by graft copolymerization of ceric ammonium nitrate and $\mathrm{CB}$ filter paper in which silver nanoparticles are being embedded as an antibacterial agent (Tankhiwale and Bajpai 2009). Other notable applications of cellulose-based hydrogels in the various fields are also summarized in Table 2.

\section{Conclusions}

Hydrogels based on biopolymer cellulose are linear polymers with a unique chemical structure having numerous hydrophilic groups enabling them to absorb and retain a huge proportion of water and thus possess a great variety of properties. The combination of versatile physicochemical properties allows hydrogels to have a wide range of industrial and biomedical applications; therefore, attracting a great scientific and industrial interest across the globe. Hence, this review is intended to focus on the promising aspects of cellulose-based hydrogels and their derivatives in biomedical applications as well as in agriculture and other industrial appliances with a meticulous compilation of the available relevant information regarding chemistry and physicochemical properties. In view of these characteristics along with their biocompatibility, biodegradability profile,

Table 2 Applications of CB hydrogels

\begin{tabular}{|c|c|c|c|}
\hline Application fields & Hydrogels used & For & References \\
\hline \multirow[t]{3}{*}{ Enzyme and catalyst support } & $\begin{array}{l}\text { Bacterial cellulose (BC)-chitosan compos- } \\
\text { ite hydrogel }\end{array}$ & $\begin{array}{l}\text { Enzyme supports for immobililization } \\
\text { lipase }\end{array}$ & Kim et al. (2017) \\
\hline & $\begin{array}{l}\text { Cellulose- } g \text {-poly(acrylic acid)/poly(vinyl } \\
\text { alcohol) semi-IPN hydrogel }\end{array}$ & Catalyst to reduce 4-nitrophenol (4-NP) & Ding et al. (2017) \\
\hline & Chitosan hydrogel & $\begin{array}{l}\text { Organocatalyst for aldol and Knoevenagel } \\
\text { reactions }\end{array}$ & Reddy et al. (2006) \\
\hline \multirow[t]{3}{*}{ Fire-extinguishing gels } & $\begin{array}{l}\text { Corn straw acrylamide-2-methylpropane- } \\
\text { sulfonic acid and acrylic acid }\end{array}$ & $\begin{array}{l}\text { Fire-extinguishing and preventing re- } \\
\text { ignition }\end{array}$ & Cheng et al. (2017) \\
\hline & Fire-Resistant Hydrogel-Fabric & Fire-resistant blankets or apparel & Illeperuma et al. (2016) \\
\hline & Chitosan based hydrogel & Prevents coal spontaneous combustion & Hu et al. (2015) \\
\hline Body water retainers & $\mathrm{CMC}$ and $\mathrm{HEC}$ & Water removal during edemas treatment & $\begin{array}{l}\text { Esposito et al. (2005), } \\
\text { Sannino et al. (2000), } \\
\text { Sannino et al. (2003) }\end{array}$ \\
\hline \multirow[t]{4}{*}{ Stomach bulking agent } & $\mathrm{CMC}$ and $\mathrm{HEC}$ & Bulking agent in dietary & Sannino et al. (2005) \\
\hline & CB hydrogel & Bulking agent for rat intestine & Sannino et al. (2006) \\
\hline & Polyethylene glycol CMC hydrogel & Urethral bulking agent for hound dogs & Sumner et al. (2012) \\
\hline & HEC hydrogel & Bulking agent during cell & Sannino et al. (2006) \\
\hline Biological fuel cells & Bacterial CB hydrogel & Microbial fuel cells & $\begin{array}{l}\text { Mashkour et al. (2016), } \\
\text { Mashkour et al. } \\
\text { (2017), Shi et al. } \\
\text { (2014) }\end{array}$ \\
\hline
\end{tabular}


cellulose-based hydrogels are poised to be an exciting and interesting excipient in the biomedical industry for the present and the future applications in wound dressing, tissue engineering and drug delivery system. The numerous uses of cellulose-based hydrogels even include the development of smart materials, advancement in healthcare and hygienic products as well as in the improvement of agriculture and wastewater treatment. All these explorations indicate that hydrogels based on cellulose hold a great promise for the applications in multidisciplinary areas and may act as a wonder material in the field of biomedical engineering and industrial sectors.

Author contributions SMFK and MAR contributed to the concept of the study and prepared the content of the review. SMFK, PPS, BH and AA drafted the manuscript. MAR and MNI finally reviewed, edited the manuscript and helped in submission process. All authors have approved the manuscript and agreed with submission to the Progress in Biomaterials. Approvals of all of the Authors' institutions have been granted to publish this work.

Funding The authors received no financial support for the research, authorship and/or publication of this article.

\section{Compliance with ethical standards}

Conflict of interest The authors have no conflicts of interest.

Research involving human participants and/or animals This article does not contain any studies involving human participants performed by any of the authors.

Open Access This article is distributed under the terms of the Creative Commons Attribution 4.0 International License (http://creativeco mmons.org/licenses/by/4.0/), which permits unrestricted use, distribution, and reproduction in any medium, provided you give appropriate credit to the original author(s) and the source, provide a link to the Creative Commons license, and indicate if changes were made.

\section{References}

Abedi-Koupai J, Asadkazemi J (2006) Effects of a hydrophilic polymer on the field performance of an ornamental plant (Cupressus arizonica) under reduced irrigation regimes. Iran Polym J 15:715. https://abedi-koupai.iut.ac.ir/sites/abedi-koupai.iut.ac.ir/files/ file_basepage/ipj-2006-11-1486.pdf

Adalat S, Wall D, Goodyear H (2007) Diaper dermatitis-frequency and contributory factors in hospital attending children. Pediatr Dermatol 24:483-488

Ahmadi F, Oveisi Z, Samani SM, Amoozgar Z (2015) Chitosan based hydrogels: characteristics and pharmaceutical applications. Res Pharm Sci 10:1

Ahmed EM (2015) Hydrogel: preparation, characterization, and applications: a review. J Adv Res 6:105-121

Alvarez-Lorenzo C, Concheiro A, Dubovik AS, Grinberg NV, Burova TV, Grinberg VY (2005) Temperature-sensitive chitosan-poly
(N-isopropylacrylamide) interpenetrated networks with enhanced loading capacity and controlled release properties. J Control Release 102:629-641

An YH, Webb D, Gutowska A, Mironov VA, Friedman RJ (2001) Regaining chondrocyte phenotype in thermosensitive gel culture. Anat Rec 263:336-341

Anal AK, Stevens WF (2005) Chitosan-alginate multilayer beads for controlled release of ampicillin. Int J Pharm 290:45-54

Andrade JD (1976) Hydrogels for medical and related applications. ACS Publications, Washington. https://doi.org/10.1021/ bk-1976-0031

Aranaz I et al (2009) Functional characterization of chitin and chitosan. Curr Chem Biol 3:203-230. https://doi. org/10.2174/187231309788166415

Aravamudhan A, Ramos DM, Nada AA, Kumbar SG (2014) Natural polymers: polysaccharides and their derivatives for biomedical applications. In: Kumbar S (ed) Natural and synthetic biomedical polymers. Elsevier, Boston, USA, pp 67-89. https://doi. org/10.1016/b978-0-12-396983-5.00004-1

Athawale VD, Lele V (2001) Recent trends in hydrogels based on starchgraft-acrylic acid: a review. Starch-Stärke 53:7-13

Atkins BL, Bashaw RN, Harper BG (1972) Absorbent product containing a hydrocelloidal composition. Google Patents. https:// patents.google.com/patent/US3669103A/en

Azlan K, Saime WNW, Liew L (2009) Chitosan and chemically modified chitosan beads for acid dyes sorption. J Environ Sci 21:296-302

Bai Y, Zhang Z, Zhang A, Chen L, He C, Zhuang X, Chen X (2012) Novel thermo-and $\mathrm{pH}$-responsive hydroxypropyl cellulose-and poly (L-glutamic acid)-based microgels for oral insulin controlled release. Carbohydr Polym 89:1207-1214

Bajpai A, Shukla SK, Bhanu S, Kankane S (2008) Responsive polymers in controlled drug delivery. Prog Polym Sci 33:1088-1118

Barleany DR, Lestari RSD, Yulvianti M, Susanto TR (2017) Acrylic acid neutralization for enhancing the production of grafted chitosan superabsorbent hydrogel. Int J Adv Sci Eng Inf Technol 7:702-708. https://doi.org/10.18517/ijaseit.7.2.2340

Bhattarai N, Ramay HR, Gunn J, Matsen FA, Zhang M (2005) PEGgrafted chitosan as an injectable thermosensitive hydrogel for sustained protein release. J Control Release 103:609-624

Bhattarai N, Gunn J, Zhang M (2010) Chitosan-based hydrogels for controlled, localized drug delivery. Adv Drug Delivery Rev 62:83-99

Bhuiyan MR, Hossain M, Zakaria M, Islam M, Uddin MZ (2017) Chitosan coated cotton fiber: physical and antimicrobial properties for apparel use. J Polym Environ 25:334-342

Bigucci F, Luppi B, Cerchiara T, Sorrenti M, Bettinetti G, Rodriguez L, Zecchi V (2008) Chitosan/pectin polyelectrolyte complexes: selection of suitable preparative conditions for colon-specific delivery of vancomycin. Eur J Pharm Sci 35:435-441

Bortolin A, Aouada FA, Mattoso LH, Ribeiro C (2013) Nanocomposite PAAm/methyl cellulose/montmorillonite hydrogel: evidence of synergistic effects for the slow release of fertilizers. J Agric Food Chem 61:7431-7439

Caló E, Khutoryanskiy VV (2015) Biomedical applications of hydrogels: a review of patents and commercial products. Eur Polym J 65:252-267

Cannazza G, Cataldo A, De Benedetto E, Demitri C, Madaghiele M, Sannino A (2014) Experimental assessment of the use of a novel superabsorbent polymer (SAP) for the optimization of water consumption in agricultural irrigation process. Water 6:2056-2069

Caykara T, Şengül G, Birlik G (2006) Preparation and swelling properties of temperature-sensitive semi-interpenetrating polymer networks composed of poly 
[(N-tert-butylacrylamide)-co-acrylamide] and hydroxypropyl cellulose macromolecular. Macromol Mater Eng 291:1044-1051

Chai Q, Jiao Y, Yu X (2017) Hydrogels for biomedical applications: their characteristics and the mechanisms behind them. Gels 3:6

Chang K, Lin J (2000) Swelling behavior and the release of protein from chitosan-pectin composite particles. Carbohydr Polym 43:163-169

Chang C, Zhang L (2011) Cellulose-based hydrogels: present status and application prospects. Carbohydr Polym 84:40-53

Chang C, Duan B, Cai J, Zhang L (2010) Superabsorbent hydrogels based on cellulose for smart swelling and controllable delivery. Eur Polym J 46:92-100

Chatterjee S, Woo SH (2009) The removal of nitrate from aqueous solutions by chitosan hydrogel beads. J Hazard Mater 164:1012-1018

Chatterjee S, Chatterjee T, Woo SH (2010) A new type of chitosan hydrogel sorbent generated by anionic surfactant gelation. Bioresour Technol 101:3853-3858

Chen H, Fan M (2008) Novel thermally sensitive pH-dependent chitosan/carboxymethyl cellulose hydrogels. Bioact Compat Polym 23:38-48

Chen J, Jo S, Park K (1995) Polysaccharide hydrogels for protein drug delivery. Carbohydr Polym 28:69-76

Chen Y, Pang XH, Dong CM (2010) Dual stimuli-responsive supramolecular polypeptide-based hydrogel and reverse micellar hydrogel mediated by host-guest chemistry. Adv Funct Mater 20:579-586

Cheng W, Hu X, Xie J, Zhao Y (2017) An intelligent gel designed to control the spontaneous combustion of coal: fire prevention and extinguishing properties. Fuel 210:826-835

Chenite A et al (2000) Novel injectable neutral solutions of chitosan form biodegradable gels in situ. Biomaterials 21:2155-2161

Chiu LL, Radisic M (2011) Controlled release of thymosin $\beta 4$ using collagen-chitosan composite hydrogels promotes epicardial cell migration and angiogenesis. J Control Release 155:376-385

Cho JH et al (2004) Chondrogenic differentiation of human mesenchymal stem cells using a thermosensitive poly ( $\mathrm{N}$-isopropylacrylamide) and water-soluble chitosan copolymer. Biomaterials 25:5743-5751

Choi K, Gao CY, Nam JD, Choi HJ (2017) Cellulose-based smart fluids under applied electric fields. Materials 10:1060

Ciolacu D, Oprea AM, Anghel N, Cazacu G, Cazacu M (2012) New cellulose-lignin hydrogels and their application in controlled release of polyphenols. Mater Sci Eng, C 32:452-463

Copello GJ, Mebert AM, Raineri M, Pesenti MP, Diaz LE (2011) Removal of dyes from water using chitosan hydrogel $/ \mathrm{SiO}_{2}$ and chitin hydrogel $/ \mathrm{SiO}_{2}$ hybrid materials obtained by the sol-gel method. J Hazard Mater 186:932-939

Coviello T, Matricardi P, Marianecci C, Alhaique F (2007) Polysaccharide hydrogels for modified release formulations. J Control Release 119:5-24

Cunha I, Barras R, Grey P, Gaspar D, Fortunato E, Martins R, Pereira L (2017) Reusable cellulose Based hydrogel sticker film applied as gate dielectric in paper electrolyte Gated transistors. Adv Funct Mater 27:1606755

Czaja WK, Young DJ, Kawecki M, Brown RM (2007) The future prospects of microbial cellulose in biomedical applications. Biomacromol 8:1-12

Das R, Ghorai S, Pal S (2013) Flocculation characteristics of polyacrylamide grafted hydroxypropyl methyl cellulose: an efficient biodegradable flocculant. Chem Eng J 229:144-152

De Gennes P-G (1979) Scaling concepts in polymer physics. Cornell university press. http://www.cornellpress.cornell.edu/ book/?GCOI $=80140100785990$
De las Heras Alarcón C, Pennadam S, Alexander C (2005) Stimuli responsive polymers for biomedical applications. Chem Soc Rev 34:276-285

Deligkaris K, Tadele TS, Olthuis W, van den Berg A (2010) Hydrogelbased devices for biomedical applications. Sens Actuar B Chem 147:765-774

Demitri C, Scalera F, Madaghiele M, Sannino A, Maffezzoli A (2013) Potential of cellulose-based superabsorbent hydrogels as water reservoir in agriculture. Int J Polym Sci. https://doi. org/10.1155/2013/435073

Ding J, Li Q, Zhao L, Li X, Yue Q, Gao B (2017) A wheat straw cellulose based semi-IPN hydrogel reactor for metal nanoparticles preparation and catalytic reduction of 4-nitrophenol. RSC Adv 7:17599-17611

Dutta S, Samanta P, Dhara D (2016) Temperature, $\mathrm{pH}$ and redox responsive cellulose based hydrogels for protein delivery. I Int J Biol Macromol 87:92-100

Ebara M et al (2014) Smart hydrogels. In: Ebara M et al (ed) Smart Biomaterials. Springer, Japan, pp 9-65

Edgar KJ, Buchanan CM, Debenham JS, Rundquist PA, Seiler BD, Shelton MC, Tindall D (2001) Advances in cellulose ester performance and application. Prog Polym Sci 26:1605-1688

Elbert DL (2011) Liquid-liquid two-phase systems for the production of porous hydrogels and hydrogel microspheres for biomedical applications: a tutorial review. Acta Biomater 7:31-56

El-Rehim H, Hegazy ESA, El-Mohdy H (2004) Radiation synthesis of hydrogels to enhance sandy soils water retention and increase plant performance. J Appl Polym Sci 93:1360-1371

Esposito A, Sannino A, Cozzolino A, Quintiliano SN, Lamberti M, Ambrosio L, Nicolais L (2005) Response of intestinal cells and macrophages to an orally administered cellulose-PEG based polymer as a potential treatment for intractable edemas. Biomaterials 26:4101-4110

Faroongsarng D, Sukonrat P (2008) Thermal behavior of water in the selected starch-and cellulose-based polymeric hydrogels. Int J Pharm 352:152-158

Fekete T, Borsa J, Takács E, Wojnárovits L (2017) Synthesis of carboxymethylcellulose/starch superabsorbent hydrogels by gammairradiation. Chem Cent J 11:46

Flory PJ, Rehner J Jr (1943) Statistical mechanics of cross-linked polymer networks I. Rubberlike elasticity. J Chem Phys 11:512-520

Friedrich S (2012) Superabsorbent polymers (SAP). In: Reinhardt HW (ed) Application of super absorbent polymers (sap) in concrete construction. Springer, Netherlands, pp 13-19. https://doi. org/10.1007/978-94-007-2733-5

Fu F, Wang Q (2011) Removal of heavy metal ions from wastewaters: a review. J Environ Manag 92:407-418

Gaharwar AK, Peppas NA, Khademhosseini A (2014) Nanocomposite hydrogels for biomedical applications. Biotechnol Bioeng 111:441-453

Gerlach G, Arndt K-F (2009) Hydrogel sensors and actuators: engineering and technology. Springer, Heidelberg. https://doi. org/10.1007/978-3-540-75645-3

Gil ES, Hudson SM (2004) Stimuli-reponsive polymers and their bioconjugates. Prog Polym Sci 29:1173-1222

Gooch JW (2011) Super Absorbent Fibers. In: Gooch JW (ed) Encyclopedic Dictionary of Polymers. Springer, New York, pp 712-714. https://doi.org/10.1007/978-1-4419-6247-8_11416

Guan H, Li J, Zhang B, Yu X (2017) Synthesis, properties, and humidity resistance enhancement of biodegradable cellulose-containing superabsorbent. Polym J Polym. https://doi. org/10.1155/2017/3134681

Guenther M, Gerlach G (2009) Hydrogels for chemical sensors. In: Gerald G (ed) Hydrogel sensors and actuators. Springer, Berlin Heidelberg, pp 165-195 
Guilherme MR et al (2015) Superabsorbent hydrogels based on polysaccharides for application in agriculture as soil conditioner and nutrient carrier: a review. Eur Polym J 72:365-385

Gupta S, Kua HW, Pang SD (2017) Combination of polypropylene fibre and superabsorbent polymer to improve physical properties of cement mortar. Mag Concrete Res 70:1-15. https://doi. org/10.1680/jmacr.17.00193

Han Z, Wang T, Dong Z, Hu Y, Yao Z (2007) Chemical stabilization of mobile dunefields along a highway in the Taklimakan Desert of China. J Arid Environ 68:260-270

Harimoto M, Yamato M, Kikuchi A (2003) Okano T Cell sheet engineering: Intelligent polymer patterned surfaces for tissue engineered liver. In: Macromolecular symposia, vol 1. Wiley Online Library, pp 231-236. https://doi.org/10.1002/masy.200390127

Harmon C (1972) Absorbent product containing a hydrocolloidal composition. Google Patents. https://patents.google.com/paten t/US3669103A/en

Hebeish A, Higazy A, El-Shafei A, Sharaf S (2010) Synthesis of carboxymethyl cellulose (CMC) and starch-based hybrids and their applications in flocculation and sizing. Carbohydr Polym 79:60-69

Hoffman AS (2001) Hydrogels for biomedical applications. Ann N Y Acad Sci 944:62-73

Hoffman AS (2012) Hydrogels for biomedical applications. Adv Drug Delivery Rev 64:18-23

Hoffman AS (2013) Stimuli-responsive polymers: biomedical applications and challenges for clinical translation. Adv Drug Delivery Rev 65:10-16

Holaday B, Waugh G, Moukaddem VE, West J, Harshman S (1995) Diaper type and fecal contamination in child day care. J Pediatr Health Care 9:67-74

Hu J, Meng H, Li G, Ibekwe SI (2012) A review of stimuli-responsive polymers for smart textile applications. Smart Mater Struct 21:053001

Hu X, Cheng W, Shao Z (2015) Novel authigenic gas foaming hydrogels for preventing coal spontaneous combustion. e-Polymers $15: 361-368$

Huh HW, Zhao L, Kim SY (2015) Biomineralized biomimetic organic/ inorganic hybrid hydrogels based on hyaluronic acid and poloxamer. Carbohydr Polym 126:130-140. https://doi.org/10.1515/ epoly-2015-0156

Illeperuma WR, Rothemund P, Suo Z, Vlassak JJ (2016) Fire-resistant hydrogel-fabric laminates: a simple concept that may save lives. ACS Appl Mater Interfaces 8:2071-2077

Islam S, Bhuiyan MR, Islam M (2017) Chitin and chitosan: structure, properties and applications in biomedical engineering. J Polym Environ 25:854-866

Ismail H, Irani M, Ahmad Z (2013) Starch-based hydrogels: present status and applications. Int J Polym Mater Polym Biomater 62:411-420

Ivanov C, Popa M, Ivanov M, Popa A (2007) Synthesis of poly (vinyl alcohol): methyl cellulose hydrogel as possible scaffolds in tissue engineering. J Optoelectron Adv Mater 9:3440-3444. http:// www.journals4free.com/link.jsp? $1=12287054$

Jafarzadeh S, Eghbal M, Jalalian A (2005) Biological and mechanical stabilization of sand dunes using super-absorbent polymers and clay mulch in Ardestan area (Isfahan). In: Proceedings of international conference on human impacts on soil quality attributes, Isfahan, IR Iran

James HM, Guth E (1943) Theory of the elastic properties of rubber. J Chem Phys 11:455-481

Jayakumar R, Prabaharan M, Kumar PS, Nair S, Tamura H (2011) Biomaterials based on chitin and chitosan in wound dressing applications. Biotechnol Adv 29:322-337
Jayaramudu T, Ko H-U, Zhai L, Li Y, Kim J (2017) Preparation and characterization of hydrogels from polyvinyl alcohol and cellulose and their electroactive behavior. Soft Mater 15:64-72

Jin R, Dijkstra PJ (2010) Hydrogels for tissue engineering applications. In: Ottenbrite RM (ed) Biomedical applications of hydrogels handbook. Springer, New York, pp 203-225. https://doi. org/10.1007/978-1-4419-5919-5

Kadokawa J-I, M-a Murakami, Takegawa A, Kaneko Y (2009) Preparation of cellulose-starch composite gel and fibrous material from a mixture of the polysaccharides in ionic liquid. Carbohydr Polym 5:180-183

Kashyap N, Kumar N, Kumar MR (2005) Hydrogels for pharmaceutical and biomedical applications. Crit Rev Ther Drug Carrier Syst. https://doi.org/10.1615/CritRevTherDrugCarrierSyst.v22. i2.10

Katepetch C, Rujiravanit R, Tamura H (2013) Formation of nanocrystalline $\mathrm{ZnO}$ particles into bacterial cellulose pellicle by ultrasonic-assisted in situ synthesis. Cellulose 20:1275-1292

Khan TA, Peh KK, Ch'ng HS (2000) Mechanical, bioadhesive strength and biological evaluations of chitosan films for wound dressing. J Pharm Pharm Sci 3:303-311

Kim HJ, Jin JN, Kan E, Kim KJ, Lee SH (2017) Bacterial cellulosechitosan composite hydrogel beads for enzyme immobilization. Biotechnol Bioprocess Eng 22:89-94

Klinpituksa P, Kosaiyakanon P (2017) Superabsorbent polymer based on sodium carboxymethyl cellulose grafted polyacrylic acid by inverse suspension polymerization. Int J Polym Sci. https://doi.org/10.1155/2017/3476921

Klouda L, Mikos AG (2008) Thermoresponsive hydrogels in biomedical applications. Eur J Pharm Biopharm 68:34-45

Knypl J, Knypl M (1993) Increased chilling stress tolerance in soybean seeds treated with poly (acrylic acid-ethyl acrylatevinyl acetate, a superabsorbent) Acta Physiologiae Plantarum (Poland). http://agro.icm.edu.pl/agro/element/bwmeta1.eleme nt.agro-article-9630dce6-ab45-4fd5-b9e2-219b751e1a92. Accessed 31 Aug 2018

Kobayashi W, Otaka S, Nagai M (1990) Statical demolition-facilitating agent. Google Patents. https://patents.google.com/paten t/US4952243A/en. Accessed 31 Aug 2018

Koetting MC, Peters JT, Steichen SD, Peppas NA (2015) Stimulusresponsive hydrogels: theory, modern advances, and applications. Mater Sci Eng R Rep 93:1-49. https://doi.org/10.1016/j. mser.2015.04.001

Kohls SJ, Baker DD, Kremer DA, Dawson JO (1999) Water-retentive polymers increase nodulation of actinorhizal plants inoculated with Frankia. Plant Soil 214:105-115

Kuckling D, Richter A, Arndt KF (2003) Temperature and pHdependent swelling behavior of poly ( $\mathrm{N}$-isopropylacrylamide) copolymer hydrogels and their use in flow control macromolecular. Mater Eng 288:144-151

Kulkarni RV, Sa B (2008) Evaluation of pH-sensitivity and drug release characteristics of (polyacrylamide-grafted-xanthan)carboxymethyl cellulose-based $\mathrm{pH}$-sensitive interpenetrating network hydrogel beads. Drug Dev Ind Pharm 34:1406-1414

Kumar V, Chaudhari C, Bhardwaj Y, Goel N, Sabharwal S (2006) Radiation induced synthesis and swelling characterization of thermo-responsive $\mathrm{N}$-isopropylacrylamide-co-ionic hydrogels. Eur Polym J 42:235-246

Kumar A, Rao KM, Han SS (2017) Synthesis of mechanically stiff and bioactive hybrid hydrogels for bone tissue engineering applications. Chem Eng J 317:119-131

Kwiecień I, Kwiecień M (2018) Application of polysaccharide-based hydrogels as probiotic delivery systems. Gels 4:47

Laftah WA, Hashim S (2013) Preparation and possible agricultural applications of polymer hydrogel composite as soil conditioner. 
In: Advanced Materials Research. Trans Tech Publ, pp 6-10. www.scientific.net/AMR.626.6

Le XT, Rioux L-E, Turgeon SL (2017) Formation and functional properties of protein-polysaccharide electrostatic hydrogels in comparison to protein or polysaccharide hydrogels. Adv Colloid Interface Sci 239:127-135

Lee KY, Mooney DJ (2001) Hydrogels for tissue engineering. Chem Rev 101:1869-1880

Lee B-Y, Kim D-S, Ryu C-M (2008) A super-absorbent polymer combination promotes bacterial aggressiveness uncoupled from the epiphytic population. Plant Pathol J 24:283-288

Li N, Bai R (2005) Copper adsorption on chitosan-cellulose hydrogel beads: behaviors and mechanisms. Sep Purif Technol 42:237-247

Li N, Bai R, Liu C (2005) Enhanced and selective adsorption of mercury ions on chitosan beads grafted with polyacrylamide via surface-initiated atom transfer radical polymerization. Langmuir 21:11780-11787

Li J, Li Y, Dong H (2008) Controlled release of herbicide acetochlor from clay/carboxylmethylcellulose gel formulations. J Agric Food Chem 6:1336-1342

Li H, Lai F, Luo R (2009a) Analysis of responsive characteristics of ionic-strength-sensitive hydrogel with consideration of effect of equilibrium constant by a chemo-electro-mechanical model. Langmuir 25:13142-13150

Li J, Jiang M, Wu H, Li Y (2009b) Addition of modified bentonites in polymer gel formulation of 2,4-D for its controlled release in water and soil. J Agric Food Chem 57:2868-2874

Li S-M, Jia N, Ma M-G, Zhang Z, Liu Q-H, Sun R-C (2011) Cellulose-silver nanocomposites: microwave-assisted synthesis, characterization, their thermal stability, and antimicrobial property. Carbohydr Polym 86:441-447

Li Y, Rodrigues J, Tomás H (2012) Injectable and biodegradable hydrogels: gelation, biodegradation and biomedical applications. Chem Soc Rev 41:2193-2221

Liu X, Zhang X, Cong J, Xu J, Chen K (2003) Demonstration of etched cladding fiber Bragg grating-based sensors with hydrogel coating. Sens Actur B Chem 96:468-472

Liu H, Zhang Y, Yao J (2014) Preparation and properties of an ecofriendly superabsorbent based on flax yarn waste for sanitary napkin applications. Fibers Polym 15:145

Lokhande H, Varadarajan P (1992) A new Guargum-based superabsorbent polymer synthesised using gamma radiation as a soil additive. Bioresour Technol 42:119-122

Long DD, Luyen DV (1996) Chitosan-carboxymethylcellulose hydrogels as supports for cell immobilization. J Macromol Sci Part A Pure Appl Chem 33:1875-1884

Luo X, Liu S, Zhou J, Zhang L (2009) In situ synthesis of $\mathrm{Fe}_{3} \mathrm{O}_{4}$ /cellulose microspheres with magnetic-induced protein delivery. $\mathrm{J}$ Mater Chem 19:3538-3545

Luppi B, Bigucci F, Cerchiara T, Zecchi V (2010) Chitosan-based hydrogels for nasal drug delivery: from inserts to nanoparticles. Expert Opinion Drug Delivery 7:811-828

Ma J, Li X, Bao Y (2015) Advances in cellulose-based superabsorbent hydrogels. RSC Adv 5:59745-59757

Magnani A, Rappuoli R, Lamponi S, Barbucci R (2000) Novel polysaccharide hydrogels: characterization and properties. Polym Adv Technol 11:488-495

Mahmoudian M, Ganji F (2017) Vancomycin-loaded HPMC microparticles embedded within injectable thermosensitive chitosan hydrogels. Prog Biomater 6:49-56

Maneerung T, Tokura S, Rujiravanit R (2008) Impregnation of silver nanoparticles into bacterial cellulose for antimicrobial wound dressing. Carbohydr Polym 72:43-51
Mano JF (2008) Stimuli-responsive polymeric systems for biomedical applications. Adv Eng Mater 10:515-527

Marler JJ, Upton J, Langer R, Vacanti JP (1998) Transplantation of cells in matrices for tissue regeneration. Adv Drug Delivery Rev 33:165-182

Marques-Marinho FD, Vianna-Soares CD (2013) Cellulose and its derivatives use in the pharmaceutical compounding practice. In: Ven GMVD (ed) Cellulose-Medical, Pharmaceutical and Electronic Applications. InTech, UK

Marsano E, Bianchi E, Viscardi A (2004) Stimuli responsive gels based on interpenetrating network of hydroxy propylcellulose and poly (N-isopropylacrylamide). Polymer 45:157-163

Martyn W, Szot P (2001) Influence of superabsorbents on the physical properties of horticultural substrates. Int Agrophys 15:87-94. http://www.old.international-agrophysics.org/artykuly/internatio nal_agrophysics/IntAgr_2001_15_2_87.pdf

Mashkour M, Rahimnejad M, Mashkour M (2016) Bacterial cellulosepolyaniline nano-biocomposite: a porous media hydrogel bioanode enhancing the performance of microbial fuel cell. J Power Sour 325:322-328

Mashkour M, Rahimnejad M, Mashkour M, Bakeri G, Luque R, Oh SE (2017) Application of wet nanostructured bacterial cellulose as a novel hydrogel bioanode for microbial fuel cells. ChemElectroChem 4:648-654

McCarthy S, Gregory K, Morgan J (2005) Antimicrobial barriers, systems, and methods formed from hydrophilic polymer structures such as chistosan. Google Patents. https://patents.google.com/ patent/US20060004314A1/en

Mechtcherine V et al (2017) Effect of superabsorbent polymers (SAP) on the freeze-thaw resistance of concrete: results of a RILEM interlaboratory study. Mater Struct 50:14

Mi F-L, Shyu S-S, Wu Y-B, Lee S-T, Shyong J-Y, Huang R-N (2001) Fabrication and characterization of a sponge-like asymmetric chitosan membrane as a wound dressing. Biomaterials 22:165-173

Michael Mercandetti AJC (2017) Wound healing and repair. Medscape Logo. https://emedicine.medscape.com/article/1298129-overv iew. Accessed December 112017

Mignon A et al (2016) Alginate biopolymers: counteracting the impact of superabsorbent polymers on mortar strength. Constr Build Mater 110:169-174

Mignon A et al (2017a) Characterization of methacrylated polysaccharides in combination with amine-based monomers for application in mortar. Carbohydr Polym 168:173-181

Mignon A, Snoeck D, Dubruel P, Van Vlierberghe S, De Belie N (2017b) Crack mitigation in concrete: superabsorbent polymers as key to success? Materials 10:237

Mignon A, Vermeulen J, Graulus G-J, Martins J, Dubruel P, De Belie N, Van Vlierberghe S (2017c) Characterization of methacrylated alginate and acrylic monomers as versatile SAPs. Carbohydr Polym 168:44-51

Mignon A, Vermeulen J, Snoeck D, Dubruel P, Van Vlierberghe S, De Belie N (2017d) Mechanical and self-healing properties of cementitious materials with $\mathrm{pH}$-responsive semi-synthetic superabsorbent polymers. Mater Struct 50:238

Mischnick P, Momcilovic D (2010) Chemical structure analysis of starch and cellulose derivatives. In: Horton D (ed) Advances in carbohydrate chemistry and biochemistry, vol 64. Elsevier, New York, pp 117-210

Mogoşanu GD, Grumezescu AM (2014) Natural and synthetic polymers for wounds and burns dressing. Int J Pharm 463:127-136

Montes JÁ, Ortega A, Burillo G (2015) Dual-stimuli responsive copolymers based on N-vinylcaprolactam/chitosan. J Radioanal Nucl Chem 303:2143-2150

Montesano FF, Parente A, Santamaria P, Sannino A, Serio F (2015) Biodegradable superabsorbent hydrogel increaseswater retention 
properties of growing media and plant growth. Agric AgricSci Procedia 4:451-458

Motornov M, Roiter Y, Tokarev I, Minko S (2010) Stimuli-responsive nanoparticles, nanogels and capsules for integrated multifunctional intelligent systems. Prog Polym Sci 35:174-211

Nagahama H, Kashiki T, Nwe N, Jayakumar R, Furuike T, Tamura H (2008) Preparation of biodegradable chitin/gelatin membranes with GlcNAc for tissue engineering applications. Carbohydr Polym 73:456-463

Nakayama A, Kakugo A, Gong JP, Osada Y, Takai M, Erata T, Kawano S (2004) High mechanical strength double-network hydrogel with bacterial cellulose. Adv Funct Mater 14:1124-1128

Navarra MA, Dal Bosco C, Serra Moreno J, Vitucci FM, Paolone A, Panero S (2015) Synthesis and characterization of cellulosebased hydrogels to be used as gel electrolytes. Membranes 5:810-823

Ngah WW, Fatinathan S (2010) Adsorption characterization of Pb(II) and $\mathrm{Cu}$ (II) ions onto chitosan-tripolyphosphate beads: kinetic, equilibrium and thermodynamic studies. J Environ Manag 91:958-969

Ngah WW, Kamari A, Koay Y (2004) Equilibrium and kinetics studies of adsorption of copper (II) on chitosan and chitosan/PVA beads. Int J Biol Macromol 34:155-161

Ngwabebhoh FA, Gazi M, Oladipo AA (2016) Adsorptive removal of multi-azo dye from aqueous phase using a semi-IPN superabsorbent chitosan-starch hydrogel. Chem Eng Res Des 112:274-288

Nie K, Pang W, Wang Y, Lu F, Zhu Q (2005) Effects of specific bonding interactions in poly ( $\varepsilon$-caprolactone $) /$ silica hybrid materials on optical transparency and melting behavior. Mater Lett 59:1325-1328

Okano T, Kikuchi A, Sakurai Y, Takei Y, Ogata N (1995) Temperature-responsive poly ( $\mathrm{N}$-isopropylacrylamide) as a modulator for alteration of hydrophilic/hydrophobic surface properties to control activation/inactivation of platelets. J Control Release $36: 125-133$

Okoh Grace (2017) Polyscaccharides in drug delivery: applications of cellulose derivatives for oral drug delivery. American Chemical Society, San Francisco

Onofrei M, Filimon A (2016) Cellulose-based hydrogels: Designing concepts, properties, and perspectives for biomedical and environmental applications Polymer Science: Research Advances, Practical Applications and Educational Aspects: 108-120. http://www.formatex.org/polymerscience1/chapters.html

Orzeszyna H, Garlikowski D, Pawlowski A (2006) Using of geocomposite with superabsorbent synthetic polymers as water retention element in vegetative layers. Int. Agrophys 20:201. http://www.old.internationalag rophysics.org/en/issue s.html?stan=detail\&vol=20\&numer $=3 \&$ paper $=615 \& \mathrm{i}=5$

Oyen M (2014) Mechanical characterisation of hydrogel materials. Int Mater Rev 59:44-59

Pal K, Banthia A, Majumdar D (2006) Development of carboxymethyl cellulose acrylate for various biomedical applications. Biomed Mater 1:85

Papadakis CM, Tsitsilianis C (2017) Responsive hydrogels from associative block copolymers: physical gelling through polyion complexation. Gels 3:3

Patrick E, Simon HAM, Thomas Romo (2016) Skin wound healing. Medscape https://emedicine.medscape.com/article/88459 4-overview. Accessed Dec 112017

Peng N, Wang Y, Ye Q, Liang L, An Y, Li Q, Chang C (2016) Biocompatible cellulose-based superabsorbent hydrogels with antimicrobial activity. Carbohydr Polym 137:59-64

Peppas NA (1987) Hydrogels in medicine and pharmacy: properties and applications, 3rd edn. CRC Press, Boca Raton. https://doi. org/10.1002/pi.4980210223
Peppas N, Bures P, Leobandung W, Ichikawa H (2000) Hydrogels in pharmaceutical formulations European. Eur J Pharm Biopharm 50:27-46

Prabaharan M, Mano JF (2006) Stimuli-responsive hydrogels based on polysaccharides incorporated with thermo-responsive polymers as novel biomaterials. Macromol Biosci 6:991-1008

Qi H (2017) Cellulose-based functional and smart materials. In: Kacprzyk J (ed) Novel Functional materials based on cellulose. Springer, pp 45-67. https://doi.org/10.1007/978-3-319-49592-7

Qiu X, Hu S (2013) "Smart" materials based on cellulose: a review of the preparations, properties, and applications. Materials 6:738-781

Radhakrishnan A, Jose GM, Kurup M (2015) PEG-penetrated chitosan-alginate co-polysaccharide-based partially and fully cross-linked hydrogels as ECM mimic for tissue engineering applications. Prog Biomater 4:101-112

Ratner BD, Hoffman AS (1976) Synthetic hydrogels for biomedical applications. ACS Publications, Washington. https://doi. org/10.1021/bk-1976-0031.ch001

Reddy KR, Rajgopal K, Maheswari CU, Kantam ML (2006) Chitosan hydrogel: a green and recyclable biopolymer catalyst for aldol and Knoevenagel reactions. New J Chem 30:1549-1552

Richter A (2010) Hydrogels for actuators. In: Gerlach G, Arndt K-F (eds) Hydrogel sensors and actuators: engineering and technology. Springer, Heidelberg, pp 221-248. https://doi. org/10.1007/978-3-540-75645-3_7

Richter A, Kuckling D, Howitz S, Gehring T, Arndt K-F (2003) Electronically controllable microvalves based on smart hydrogels: magnitudes and potential applications. J Microelectromech Syst 12:748-753

Richter A, Howitz S, Kuckling D, Arndt K-F (2004) Influence of volume phase transition phenomena on the behavior of hydrogelbased valves. Sens Actuators B Chem 99:451-458. https://doi. org/10.1007/978-3-540-75645-3

Rizwan M et al (2017) pH Sensitive hydrogels in drug delivery: brief history, properties, swelling, and release mechanism, material selection and applications. Polymers 9:137

Rodrigues FH, Spagnol C, Pereira AG, Martins AF, Fajardo AR, Rubira AF, Muniz EC (2014) Superabsorbent hydrogel composites with a focus on hydrogels containing nanofibers or nanowhiskers of cellulose and chitin. J Appl Polym 131:1-1

Roman M (2017) Cellulose nanocrystal conjugates for drug delivery and bioimaging applications. American Chemical Society, San Francisco. http://cell.sites.acs.org/meetings/2017_ACSsp ring/253_CELL_Draft_Final\%20Program_3-2-2017.pdf

Ross P, Mayer R, Benziman M (1991) Cellulose biosynthesis and function in bacteria. Microbiol Rev 55:35-58

Roy N, Saha N, Kitano T, Saha P (2012) Biodegradation of PVPCMC hydrogel film: a useful food packaging material. Carbohydr Polym 89:346-353

Sánchez-Orozco R, Timoteo-Cruz B, Torres-Blancas T, Ureña-Núñez F (2017) Valorization of superabsorbent polymers from used disposable diapers as soil moisture conditioner. Int J Res. https ://doi.org/10.5281/zenodo.569984

Sanna R et al (2013) Poly (N-vinylcaprolactam) nanocomposites containing nanocrystalline cellulose: a green approach to thermoresponsive hydrogels. Cellulose 20:2393-2402

Sannino A et al (2000) Cellulose-based hydrogels as body water retainers. J Mater Sci Mater Med 11:247-253

Sannino A, Esposito A, Rosa AD, Cozzolino A, Ambrosio L, Nicolais L (2003) Biomedical application of a superabsorbent hydrogel for body water elimination in the treatment of edemas. J Biomed Mater Res, Part A 67:1016-1024

Sannino A, Mensitieri G, Nicolais L (2004) Water and synthetic urine sorption capacity of cellulose-based hydrogels under a compressive stress field. J Appl Polym Sci 91:3791-3796 
Sannino A, Pappada S, Madaghiele M, Maffezzoli A, Ambrosio L, Nicolais L (2005) Crosslinking of cellulose derivatives and hyaluronic acid with water-soluble carbodiimide. Polymer 46:11206-11212

Sannino A, Madaghiele M, Lionetto M, Schettino T, Maffezzoli A (2006) A cellulose-based hydrogel as a potential bulking agent for hypocaloric diets: an in vitro biocompatibility study on rat intestine. J Appl Polym Sci 102:1524-1530

Sannino A, Demitri C, Madaghiele M (2009) Biodegradable cellulosebased hydrogels: design and applications. Materials 2:353-373

Satarkar NS, Biswal D, Hilt JZ (2010) Hydrogel nanocomposites: a review of applications as remote controlled biomaterials. Soft Matter 6:2364-2371

Schröfl C, Snoeck D, Mechtcherine V (2017) A review of characterisation methods for superabsorbent polymer (SAP) samples to be used in cement-based construction materials: report of the RILEM TC 260-RSC. Mater Struct 50:197

Seki Y, Altinisik A, Demircioğlu B, Tetik C (2014) Carboxymethylcellulose (CMC)-hydroxyethylcellulose (HEC) based hydrogels: synthesis and characterization. Cellulose 21:1689-1698

Seliktar D (2012) Designing cell-compatible hydrogels for biomedical applications. Science 336:1124-1128

Shamma RN, Elkasabgy NA, Mahmoud AA, Gawdat SI, Kataia MM, Hamid MAA (2017) Design of novel injectable in situ forming scaffolds for non-surgical treatment of periapical lesions: invitro and in vivo evaluation. Int J Pharm 521:306-317. https ://doi.org/10.1016/j.ijpharm.2017.02.058

Shen X, Shamshina JL, Berton P, Gurau G, Rogers RD (2016) Hydrogels based on cellulose and chitin: fabrication, properties, and applications. Green Chem 18:53-75

Shi Z, Li Y, Chen X, Han H, Yang G (2014) Double network bacterial cellulose hydrogel to build a biology-device interface. Nanoscale 6:970-977

Shimizu T, Yamato M, Kikuchi A, Okano T (2003) Cell sheet engineering for myocardial tissue reconstruction. Biomaterials 24:2309-2316

Shiroyanagi Y, Yamato M, Yamazaki Y, Toma H, Okano T (2003) Transplantable urothelial cell sheets harvested noninvasively from temperature-responsive culture surfaces by reducing temperature. Tissue Eng 9:1005-1012

Sklenář Z, Vitková Z, Herdová P, Horáčková K, Šimunková V (2013) Formulation and release of alaptide from cellulose-based hydrogels. Acta Vet Brno 81:301-306

Smitha B, Sridhar S, Khan A (2004) Polyelectrolyte complexes of chitosan and poly (acrylic acid) as proton exchange membranes for fuel cells. Macromolecules 37:2233-2239

Snoeck D, Pel L, De Belie N (2017) The water kinetics of superabsorbent polymers during cement hydration and internal curing visualized and studied by NMR. Sci Rep 7:9514

Sperling LH (1994) Interpenetrating polymer networks an overview. ACS Publications, Washington

Sumner JP, Hardie RJ, Henningson JN, Drees R, Markel MD, Bjorling D (2012) Evaluation of submucosally injected polyethylene glycol-based hydrogel and bovine cross-linked collagen in the canine urethra using cystoscopy, magnetic resonance imaging and histopathology. Vet Surg 41:655-663

Tallawi M, Rosellini E, Barbani N, Cascone MG, Rai R, Saint-Pierre G, Boccaccini AR (2015) Strategies for the chemical and biological functionalization of scaffolds for cardiac tissue engineering: a review. J R Soc Interface 12:20150254

Tan J, Kang H, Liu R, Wang D, Jin X, Li Q, Huang Y (2011) Dualstimuli sensitive nanogels fabricated by self-association of thiolated hydroxypropyl cellulose. Polym Chem 2:672-678

Tang H, Chang C, Zhang L (2011) Efficient adsorption of Hg $2+$ ions on chitin/cellulose composite membranes prepared via environmentally friendly pathway. Chem Eng J 173:689-697
Tang H, Zhou W, Lu A, Zhang L (2014) Characterization of new sorbent constructed from $\mathrm{Fe}_{3} \mathrm{O}_{4}$ /chitin magnetic beads for the dynamic adsorption of $\mathrm{Cd}^{2+}$ ions. J Mater Sci 49:123-133

Tankhiwale R, Bajpai S (2009) Graft copolymerization onto cellulose-based filter paper and its further development as silver nanoparticles loaded antibacterial food-packaging material. Colloids Surf B 69:164-168

Thakur VK, Thakur MK (2014) Recent trends in hydrogels based on psyllium polysaccharide: a review. J Cleaner Prod 82:1-15

Thévenot DR, Toth K, Durst RA, Wilson GS (2001) Electrochemical biosensors: recommended definitions and classification. Biosens Bioelectron 16:121-131

Tokarev I, Minko S (2009) Stimuli-responsive hydrogel thin films. Soft Matter 5:511-524

Tokareva I, Minko S, Fendler JH, Hutter E (2004) Nanosensors based on responsive polymer brushes and gold nanoparticle enhanced transmission surface plasmon resonance spectroscopy. J Am Chem Soc 126:15950-15951

Tomatsu I, Peng K, Kros A (2011) Photoresponsive hydrogels for biomedical applications. Adv Drug Delivery Rev 63:1257-1266

Topolkaraev VA, Soerens DA (2003) Methods of making humidity activated materials having shape-memory. Google Patents. https ://patents.google.com/patent/US6627673

Tosh B (2015) Esterification and etherification of cellulose synthesis and application of cellulose derivatives cellulose and cellulose derivatives synthesis, modification and applications. Nova Science Publishers, New York, pp 259-298

Van der Linden HJ, Herber S, Olthuis W, Bergveld P (2003) Stimulussensitive hydrogels and their applications in chemical (micro) analysis. Analyst 128:325-331

Villalba-Rodríguez AM, Dhama K, Iqbal HMN (2017) Biomaterialsbased hydrogels and their drug delivery potentialities. Int J Pharmacol 13:9. https://doi.org/10.3923/ijp.2017.864.873

Vlaia L, Coneac G, Olariu I, Vlaia Vi, Lupuleasa D (2016) Cellulosederivatives-based hydrogels as vehicles for dermal and transdermal drug delivery. In: Majee SB (ed) Emerging concepts in analysis and applications of hydrogels. InTech, UK

Wall FT (1942) Statistical thermodynamics of rubber. J Chem Phys $10: 485-488$

Wang Y, Chen L (2011) Impacts of nanowhisker on formation kinetics and properties of all-cellulose composite gels. Carbohydr Polym 83:1937-1946

Wang W, Wang A (2010) Synthesis and swelling properties of $\mathrm{pH}$ sensitive semi-IPN superabsorbent hydrogels based on sodium alginate-g-poly (sodium acrylate) and polyvinylpyrrolidone. Carbohydr Polym 80:1028-1036

Wang J, Zhou X, Xiao H (2013) Structure and properties of cellulose/ poly (N-isopropylacrylamide) hydrogels prepared by SIPN strategy. Carbohydr Polym 94:749-754

Ward MA, Georgiou TK (2011) Thermoresponsive polymers for biomedical applications. Polymers 3:1215-1242

Woodhouse J, Johnson M (1991) Effect of superabsorbent polymers on survival and growth of crop seedlings. Agric Water Manage 20:63-70

Xu Y, Zhan C, Fan L, Wang L, Zheng H (2007) Preparation of dual crosslinked alginate-chitosan blend gel beads and in vitro controlled release in oral site-specific drug delivery system. Int J Pharm 336:329-337

Xu F, Zhu Y, Liu F, Nie J, Ma J, Yang W (2010) Comb-shaped conjugates comprising hydroxypropyl cellulose backbones and lowmolecular-weight poly ( $\mathrm{N}$-isopropylacryamide) side chains for smart hydrogels: synthesis, characterization, and biomedical applications. Bioconjugate Chem 21:456-464

Yamato M, Utsumi M, Kushida A, Konno C, Kikuchi A, Okano T (2001) Thermo-responsive culture dishes allow the intact harvest 
of multilayered keratinocyte sheets without dispase by reducing temperature. Tissue Eng 7:473-480

Yamato M, Konno C, Utsumi M, Kikuchi A, Okano T (2002) Thermally responsive polymer-grafted surfaces facilitate patterned cell seeding and co-culture. Biomaterials 23:561-567

Yang T (2012) Mechanical and swelling properties of hydrogels. KTH Royal Institute of Technology. http://urn.kb.se/resol ve?urn=urn\%3Anbn\%3Ase\%3Akth\%3Adiva-105539

Yang JM, Lin HT (2004) Properties of chitosan containing PP-g-AA-gNIPAAm bigraft nonwoven fabric for wound dressing. J Membr Sci 243:1-7. https://doi.org/10.1016/j.memsci.2004.03.019

Yang S, Fu S, Liu H, Zhou Y, Li X (2011) Hydrogel beads based on carboxymethyl cellulose for removal heavy metal ions. J Appl Polym Sci 119:1204-1210

Yang J, Han C-R, Duan J-F, Ma M-G, Zhang X-M, Xu F, Sun R-C (2013) Synthesis and characterization of mechanically flexible and tough cellulose nanocrystals-polyacrylamide nanocomposite hydrogels. Cellulose 20:227-237

Yuan P (2013) Design, fabrication, and application of stimuli-responsive hydrogel actuators. University of Illinois at Urbana-Champaign. http://hdl.handle.net/2142/46812

Zhang L-M, Yang C, Yan L (2005) Perspectives on: strategies to fabricate starch-based hydrogels with potential biomedical applications. J Bioact Compat Polym 20:297-314
Zheng Y, Wang A (2009) Evaluation of ammonium removal using a chitosan-g-poly (acrylic acid)/rectorite hydrogel composite. J Hazard Mater 171:671-677

Zhou D, Zhang L, Zhou J, Guo S (2004) Cellulose/chitin beads for adsorption of heavy metals in aqueous solution. Water Res 38:2643-2650

Zhou D, Zhang L, Guo S (2005) Mechanisms of lead biosorption on cellulose/chitin beads. Water Res 39:3755-3762

Zhou H et al (2014) Temperature/pH sensitive cellulose-based hydrogel: synthesis, characterization, loading, and release of model drugs for potential oral drug delivery. BioResources 10:760-771

Zohuriaan-Mehr MJ, Kabiri K (2008) Superabsorbent polymer materials: a review. Iran Polym J 17:451. http://www.sid.ir/en/journal/ ViewPaper.aspx?FID $=81320080606$

Zohuriaan-Mehr M, Omidian H, Doroudiani S, Kabiri K (2010) Advances in non-hygienic applications of superabsorbent hydrogel materials. J Mater Sci 45:5711-5735

Publisher's Note Springer Nature remains neutral with regard to jurisdictional claims in published maps and institutional affiliations. 